\title{
Numerical and Experimental Study on Curing- induced Residual Stress and Deformation of Adhesively Bonded Sandwich Structures of Dissimilar Materials
}

Jianjun Li ( $\nabla$ lijianjun@tongji.edu.cn )

Tongji University

Wenfeng Zhu

Tongji University

Yuanhui Li

Tongji University

Genglin Tang

Tongji University

\section{Research Article}

Keywords: Dissimilar materials, Sandwich structures , Adhesively bonded , Multi-physics fields, Mismatch deformation, Curing induced

Posted Date: May 11th, 2021

DOl: https://doi.org/10.21203/rs.3.rs-507701/v1

License: (c) (i) This work is licensed under a Creative Commons Attribution 4.0 International License. Read Full License

Version of Record: A version of this preprint was published at The International Journal of Advanced Manufacturing Technology on February 11th, 2022. See the published version at https://doi.org/10.1007/s00170-021-08480-7. 


\title{
Numerical and experimental study on curing-induced residual stress and deformation of adhesively bonded sandwich structures of dissimilar materials
}

\author{
Jianjun Li, Wenfeng Zhu*, Yuanhui Li, Genglin Tang \\ School of Mechanical Engineering, Tongji University, Shanghai, China
}

Corresponding author :Wenfeng Zhu*

Mobile phone: +8613917863715

E-mail: zhuwenfeng@ tongji.edu.cn

Postal code: 201804

Address: School of Mechanical Engineering, Tongji University, Shanghai, China

\section{Abstract}

Adhesively bonded sandwich structure with dissimilar materials becomes an important means of lightweight for the next generation of autobody closure panels. However, during the baking process, the complicated change of physical properties of the adhesive can lead to structural mismatch deformation. In this paper, a multi-physics coupling numerical model of one-component hemming adhesive during the curing process is proposed, to reveal the deformation mechanism of adhesively bonded sandwich structures quantitatively. The material constitutive model of the hemming adhesive is established, considering evolution of curing properties. The curing process of typical aluminum alloy and steel bonded sandwich structure is simulated in COMSOL Multiphysics. The predicted surface deformation of the component is verified by experiment using Digital Image Correlation (DIC) technique, which captures the full-field displacement in a non-intrusive manner. Then, the development process of surface deformation of the outer panel and residual internal stress of the adhesive layer is analyzed, and the influence of temperature cycle on the maximum deformation of the component is discussed. The results show at the beginning of holding stage, the deformed component slightly rebounds, which is related to the chemical shrinkage. Mechanical strain caused by the coefficient of thermal expansion (CTE) and stiffness difference of the inner and outer panels is dominant in the adhesive layer. Reducing the curing rate and maximum holding temperature can reduce the overall deformation of the structure. 


\section{Keywords}

Dissimilar materials - Sandwich structures - Adhesively bonded • Multi-physics fields $\cdot$ Mismatch deformation $\cdot$ Curing induced

\section{Introduction}

Whether traditional fuel vehicles need to meet increasingly stringent environmental regulations, or new energy vehicles continue to improve the endurance mileage, autobody lightweight is a common and key basic technology [1-2]. The steel aluminum hybrid structure not only gives full play to the strength and manufacturing cost advantages of high-strength steel, but also takes into account the weight reduction and energy absorption characteristics of aluminum, and has become an effective way to lightweight the new generation of autobody [3]. Therefore, steel-aluminum hybrid closure panels with sandwich structure, such as doors, hoods and deck lids, gradually become the focus of lightweight research.

The sandwich structure is composed of the hemming adhesive, the inner panel and the outer panel, which are connected by the composite process of gluing, hemming and baking [4]. In general, the research and application of similar materials connection technology have been relatively mature [5]. However, when dissimilar materials are used, due to the significant differences in the stiffness and CTE, large residual stress and warping deformation of the structure are generated in the baking condition [6-7], which seriously affect the assembly accuracy and appearance perception quality of the closure panels. Therefore, in order to restrain and eliminate the structure mismatch, it is necessary to understand the deformation mechanism.

Compared with experiments, finite element simulation can effectively predict deformation and internal stress of the structure and reduce the cost of experiments, thus it has become an important research method. Due to the complex changes in the baking process, the constitutive model of the adhesive becomes the key to accurate numerical simulation. In early studies, linear model [8-9] was mainly used in the adhesive-bonded structure. As it can not describe the stress relaxation phenomenon, viscoelastic model [10] was gradually adopted. These models ignored the curing properties of the adhesive 
and assumed that the structure was in stress-free state before cooling. However, subsequent studies showed that many factors, such as curing temperature [11], curing rate [12], and multi-step method [13], could affect the final results. It can be seen that neglecting the mechanical properties of the adhesive in the heating and holding stage was easy to lead to large prediction deviation. Therefore, in order to achieve accurate prediction, some scholars proposed a multi-phase model covering the whole temperature cycle [14-17]. These models have been applied in coating process [15], resin mold material [16] and electronic packaging [17]. It provides a reference for the establishment of material constitutive model of the hemming adhesive.

In summary, the deformation mechanism of the adhesive-bonded sandwich structure of dissimilar materials in the baking process is not clear. It seriously limits the design and application of the new generation of material hybrid autobody closure panels. In this study, a multi-physics coupling numerical model of one-component adhesive during the curing process is proposed. The material constitutive model of the hemming adhesive is established, considering evolution of curing properties. The curing process of typical aluminum alloy and steel bonded sandwich structure is simulated in Comsol Multiphysics. The predicted transient surface deformation is verified by DIC measurement experiment. Then, the development of the internal stress of the adhesive and the deformation of the structure are analyzed, and maximum deformation of the component under different temperature cycles is discussed.

\section{Multi-physics fields coupling model}

\subsection{Governing equations}

During the baking process, deformation process of the sandwich structure is a multi-physics fields involving heat transfer, material transformation and structural mechanics. The heat convection occurs between the outer surface of the structure and the surrounding air, while the heat transfer occurs inside. The temperature of air is heated from room temperature $T_{0}$ to the highest temperature $T_{\mathrm{b}}$ at a certain heating rate $K_{1}$. After holding for a period of time, the temperature drops to room temperature $T_{0}$ at a 
certain rate $K_{2}$. The differential equation of this transient heat transfer process is as follows [18-19]

$$
\rho c \frac{\partial T}{\partial t}=k_{x} \frac{\partial^{2} T}{\partial x^{2}}+k_{y} \frac{\partial^{2} T}{\partial y^{2}}+k_{z} \frac{\partial^{2} T}{\partial z^{2}}+\rho H_{u} \frac{d \alpha}{d t}
$$

where $\rho$ and $c$ represent the density and specific heat of the material, $k_{i}$ is the heat conductivity coefficients $(i=x, y, z), T$ represents the temperature, $\alpha$ and $d \alpha / d t$ represent the curing degree and instantaneous curing rate of the hemming adhesive respectively, and $H_{u}$ represents the total amount of heat released by the adhesive after curing reaction. The thermal convection boundary condition of the component is

$$
k_{i} \frac{\partial T}{\partial n}+h_{e f f}\left(T_{s}-T_{r e f}\right)=0
$$

where $T_{s}$ is the temperature of the component surface, $T_{r e f}$ is the heating environment temperature, $h_{\text {eff }}$ is the equivalent convection heat transfer coefficient of the air $\left(25 \mathrm{~W} / \mathrm{m}^{2} \cdot \mathrm{K}\right)$.

The hemming adhesive of Type Dow $1496 \mathrm{~V}$ is a kind of one-component thermosetting resin adhesive commonly used in the autobody closure panels. Differential scanning calorimeter STA449C/3/G (Netzsch, Germany) is used to obtain the data in the curing process. The curing phase transition model of the hemming adhesive is an autocatalytic Kamal-sourour model [20], which is obtained by Málek method [21]

$$
\frac{d \alpha}{d t}=A \alpha^{m}(1-\alpha)^{n} \exp \left[-\frac{E_{a}}{R T}\right]
$$

where $R$ is the universal gas constant of $8.314 \mathrm{~J} / \mathrm{mol} \cdot \mathrm{K}, A$ is exponential factor, $E_{\mathrm{a}}$ is reaction activation energy, and $m$ and $n$ are reaction order, as shown in Table 1.

In the viscoelastic structure field, the bulk modulus and shear modulus generally be used to establish the relationship between stress and strain [22]. The constitutive equation can be expressed as

$$
\sigma_{i j}=G(\alpha, t, T) \varepsilon_{i j}^{d e v}+\delta_{i j} K(\alpha, t, T) \varepsilon_{o p}
$$

which $\sigma_{i j}$ is Cauchy stress tensor, $\varepsilon_{i j}^{d v}$ is strain deviator tensor, $\delta_{i j}$ is the Kronecker symbol and $\varepsilon_{o p}$ is strain sphere tensor. $G(\alpha, t, T)$ and $K(\alpha, t, T)$ represent shear modulus and bulk modulus, respectively. 
In the coupled physical field composed of Eq. (1)-(4), elastic and thermal strains are mainly produced in the aluminum alloy and steel panel. In addition to the elastic, thermal and chemical strains, the material stiffness of the adhesive will also change with the curing degree, temperature and time.

\subsection{Constitutive model of the hemming adhesive}

In order to improve the prediction accuracy and reduce the testing and calculation time of complex parameters, a four-phase curing constitutive model of the hemming adhesive is established during the baking process based on the previous studies [14-17], as shown in Fig. 1.

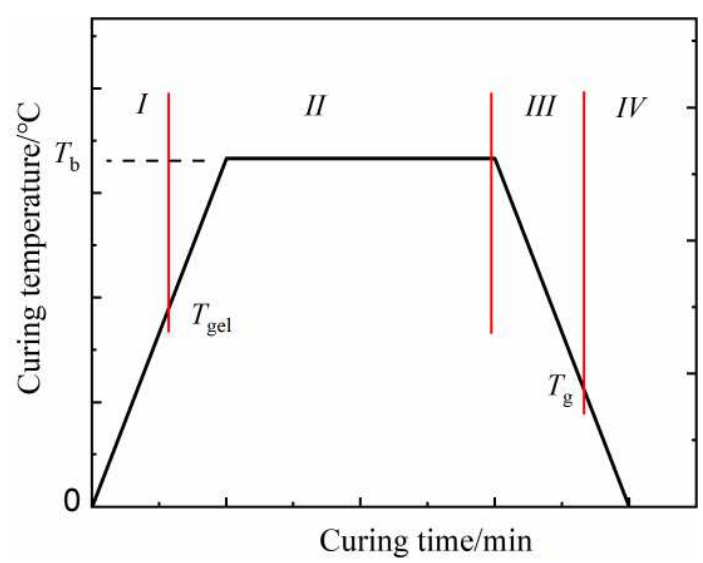

Fig. 1 Diagram of four-phase curing model of the adhesive under temperature cycle

During the phase I, as the temperature is lower than the gel temperature $T_{\text {gel }}$, the adhesive can flow and relax rapidly under the action of external force [15], thus it can offset the changes in the movement of the panels. Therefore, the effect of mechanical properties in this phase can be ignored. When the temperature exceeds $T_{\text {gel }}$, the initial shear modulus is established, and the mechanical properties mainly occur in phases II, III and IV. The total strain consists of three parts

$$
\varepsilon_{i j}=\varepsilon_{i j}^{e x}+\varepsilon_{i j}^{c h}+\varepsilon_{i j}^{t h}
$$

where $\varepsilon_{i j}^{e x}$ is mechanical strain, $\varepsilon_{i j}^{c h}$ is chemical strain and $\varepsilon_{i j}^{t h}$ is thermal strain.

\subsubsection{Phase II}


Theoretically, the bulk modulus of the adhesive is related to the curing characteristics. However, when the curing degree changes, it is found that the bulk modulus of the hemming adhesive is almost unchanged, which is similar to other polymers [23]. Therefore, this model assumes that the bulk modulus is only depends the temperature. Based on the Tait equation, the modified bulk modulus is used in same way as in Literature $[16,17]$

$$
\begin{gathered}
K(T)=\left[k_{1} s_{0}+\frac{1}{2} k_{2} s_{0}\left(1+\tanh \left(c_{1}\left(T-T_{g}\right)\right)\right)+\frac{\mathrm{C}}{B(T)}\right]^{-1} \\
B(T)=b_{1} \exp \left(-b_{2} T\right)
\end{gathered}
$$

where $s_{0}, b_{1}$ and $b_{2}$ are fitted constants of the adhesive material. The Tait constant $\mathrm{C}$ is 0.0894 . The relationship between Pressure Volume Temperature (P-V-T) [23-24] is measured by high pressure dilatometer PVT6000 (Gotech, China). According to the measurement method of literature [16], the relevant parameters are shown in Table 1.

The establishment of shear modulus starts from the gel point $T_{\text {gel }}$. During the heating and holding phase, a high elastic function related to curing degree is used [10]

$$
G(\alpha)=G^{\text {frnal }}\left(\frac{\alpha^{2}-\alpha_{g e l}^{2}}{1-\alpha_{g e l}^{2}}\right)^{\frac{8}{3}}
$$

Where $G^{\text {final }}$ is the shear modulus of the fully cured adhesive, $\alpha_{g e l}$ is the curing degree of the adhesive at $T_{\text {gel }}$.

The thermal strain can be expressed as

$$
\varepsilon_{i j}^{\text {ih }}=C T E_{a d h} \cdot\left(T-T_{e x t}\right)
$$

Theoretically, the CTE of adhesive is changing with pressure, temperature and volume. As the baking process is completed under atmospheric pressure, it has nothing to do with pressure. The CTE is modeled in the same way as in literature [16-17]

$$
C T E_{\text {adh }}=k_{1}+\frac{1}{2} k_{2}\left(1+\tanh \left[c_{1}\left(T-T_{g}\right)\right]\right)
$$

Although the chemical shrinkage and thermal expansion strains coexist, and the separation of the two is helpful to understand the process of stress generation. Many scholars have adopted linear simplified models related to curing degree [25]

$$
\varepsilon_{i j}^{i h}=\left(\alpha-\alpha_{g e l}\right) \varepsilon_{\max }^{c h}
$$


where $\varepsilon_{\max }^{c h}$ is the volume chemical shrinkage between the gel point and the complete cure.

Table 1 Main constitutive model parameters of the adhesive

\begin{tabular}{cccccccc}
\hline$A(1 / \mathrm{min})$ & $E(\mathrm{KJ} / \mathrm{mol})$ & $m$ & $n$ & $V_{0}\left(\mathrm{~cm}^{3} / \mathrm{g}\right)$ & $k_{1}\left(1 /{ }^{\circ} \mathrm{C}\right)$ & $k_{2}\left(1 /{ }^{\circ} \mathrm{C}\right)$ & $b_{1}(\mathrm{MPa})$ \\
\hline $5.89 \mathrm{E} 10$ & 91.62 & 0.61 & 1.72 & 0.8251 & $1.5 \mathrm{E}-4$ & $2.7 \mathrm{E}-4$ & 428.1 \\
$b_{2}\left(1 /{ }^{\circ} \mathrm{C}\right)$ & $c_{1}\left(1 /{ }^{\circ} \mathrm{C}\right)$ & $s_{0}\left({ }^{\circ} \mathrm{C} / \mathrm{MPa}\right)$ & $q_{\text {gel }}$ & $T_{\mathrm{g}}\left({ }^{\circ} \mathrm{C}\right)$ & $G_{\text {final }}(\mathrm{MPa})$ & $K_{\text {adh }}\left(\mathrm{W} / \mathrm{m}^{\circ} \mathrm{C}\right)$ & - \\
0.01592 & 0.0224 & 3.34 & 0.45 & $88 \sim 91$ & 58.3 & 0.2 & - \\
\hline
\end{tabular}

\subsection{2 phases III and IV}

During the cooling phase III and IV, the adhesive has been completely cured, and the chemical shrinkage has stopped. The model of bulk modulus is the same as the Eq. (6)-(7), and the model of CTE is the same as Eq. (10). A linear viscoelastic relaxation function is used for the fully cured shear modulus [16]

$$
G(t)=G_{\infty}+\sum_{m=1}^{N} G_{m} \exp \left(-t / \tau_{m}\right)
$$

The deviator stress and strain can be expressed as follows

$$
\sigma_{i j}^{d e v}=2 G_{\infty} \varepsilon_{i j}^{d e v}+2 \sum_{m=1}^{N} G_{m} q_{m}
$$

where $G_{\infty}$ is the equilibrium modulus, $G_{m}$ and $\tau_{m}$ are the relaxation modulus and relaxation time of the m-th Maxwell unit. The stress relaxation parameters of the hemming adhesive are obtained by torsional test system with temperature chamber MTS809 (MTS, USA). According to the measurement method of literature [16], the fitted ten-order main shear relaxation modulus spectrum is shown in Table 2.

The mechanical relationship between any point and the reference temperature point can be established by using the time-temperature equivalent equation. The difference between phase III and phase IV lies in the time temperature equivalent equation. In phase III, WLF Equation [16] is used for the region above the glass transition temperature. In phase IV, Arrhenius Equation [26] is applied to the region of secondary 
transition temperature

$$
\log a_{T}= \begin{cases}\frac{C_{1}\left(T-T_{r e f}\right)}{\left(C_{2}+T-T_{r e f}\right)} & T_{r e f}<T<T_{r e f}+100 \\ \frac{E}{2.303}\left(\frac{1}{T}-\frac{1}{T_{g}}\right) & T<T_{r e f}\end{cases}
$$

where $T_{r e f}$ is the reference temperature and $T_{\mathrm{g}}$ is the glass transition temperature. The constant $C_{1}$ is 17.44 and $C_{2}$ is 51.6 .

Table 2 Ten-order shear relaxation modulus spectrum of the adhesive (G/MPa, $\tau / \mathrm{h})$

\begin{tabular}{ccccccccccc}
\hline$G_{\infty}$ & $G_{1}$ & $G_{2}$ & $G_{3}$ & $G_{4}$ & $G_{5}$ & $G_{6}$ & $G_{7}$ & $G_{8}$ & $G_{9}$ & $G_{10}$ \\
\hline 100.4 & 28.3 & 29.3 & 37.9 & 28.4 & 27.9 & 46.7 & 89.3 & 79.4 & 94.6 & 66.4 \\
$\tau_{0}$ & $\tau_{1}$ & $\tau_{2}$ & $\tau_{3}$ & $\tau_{4}$ & $\tau_{5}$ & $\tau_{6}$ & $\tau_{7}$ & $\tau_{8}$ & $\tau_{9}$ & $\tau_{10}$ \\
- & $2.1 \mathrm{E} 3$ & $2.4 \mathrm{E} 10$ & $5.2 \mathrm{E} 3$ & $7.2 \mathrm{E} 3$ & $2.4 \mathrm{E} 3$ & $2.5 \mathrm{E} 6$ & $1.8 \mathrm{E} 4$ & $2.2 \mathrm{E} 3$ & $4.3 \mathrm{E} 8$ & $5.6 \mathrm{E} 9$ \\
\hline
\end{tabular}

\subsection{Material model of metal sheet}

The material of outer panel studied is aluminum alloy AA6016-T4, which has good mechanical and bending characteristics, widely used in automobile outer panels. The inner panel material is cold-rolled steel $\mathrm{DC} 04$, and the main parameters are shown in Table 3. During the process of curing, as there is no plastic deformation, the linear thermoelastic constitutive model is used.

Table 3 Main parameters of metal materials

\begin{tabular}{cccccc}
\hline Material & $\begin{array}{c}\text { Specific heat } \\
\text { name }\end{array}$ & $\begin{array}{c}\text { CTE } \\
(\mathrm{J} / \mathrm{Kg} \cdot \mathrm{K})\end{array}$ & $\begin{array}{c}\text { Shear } \\
\text { modulus } \\
\left(10^{-6} / \mathrm{K}\right)\end{array}$ & $\begin{array}{c}\text { Bulk } \\
\text { modulus } \\
(\mathrm{MPa})\end{array}$ & $\begin{array}{c}\text { Thermal } \\
\text { conductivity } \\
(\mathrm{W} / \mathrm{m} \cdot \mathrm{K})\end{array}$ \\
\hline AA6016-T4 & 896 & 23.2 & 26.5 & 57.5 & 167 \\
DC04 & 509 & 12.5 & 80.7 & 175 & 50.2 \\
\hline
\end{tabular}

\section{Simulation and experiment}

\subsection{Numerical simulation}


A typical flat surface-straight edge panels [4] is taken as the research object, and the aluminum alloy and steel bonded sandwich structure is shown in Fig. 2. The thickness of aluminum alloy panel, steel panel and upper / lower adhesive layer are $0.8 \mathrm{~mm}, 0.8$ $\mathrm{mm}$ and $0.2 \mathrm{~mm}$ respectively, and the overall component thickness is $2.8 \mathrm{~mm}$. One end is unrestrained and the other is fixed. According to the requirements of the autobody baking process [3], the component is cured and connected by thermal convection between the structure surface and the surrounding air. A curing temperature cycle of heating and cooling $4 \mathrm{~K} / \mathrm{min}$, maximum temperature $170{ }^{\circ} \mathrm{C}$ and holding time $30 \mathrm{~min}$ is adopted, in accordance with the material characteristics of the hemming adhesive.

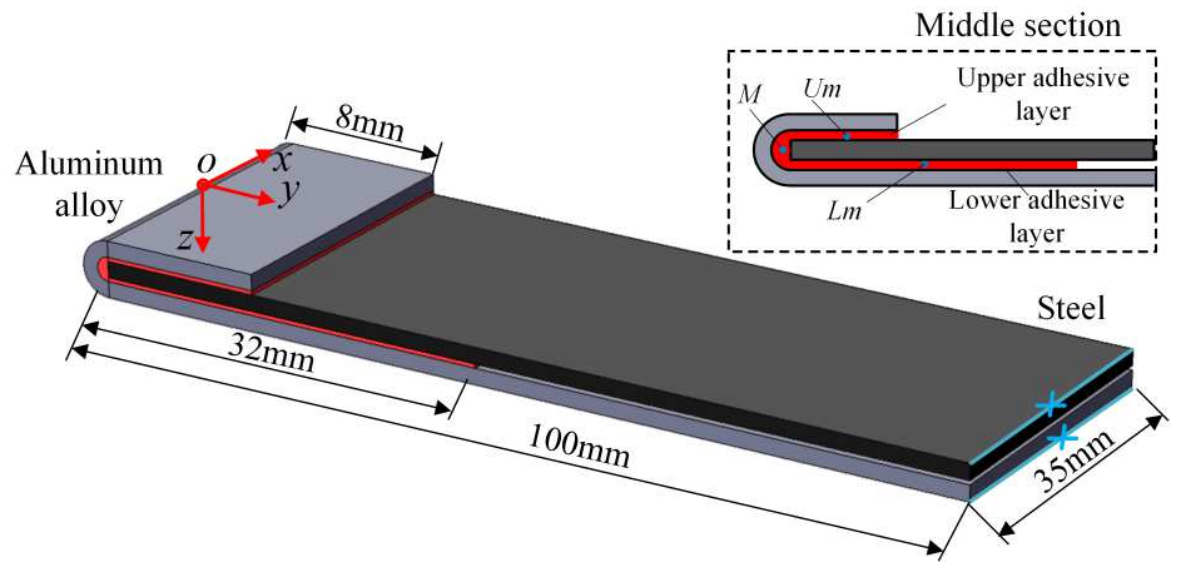

Fig. 2 Geometric dimensions of adhesively bonded sandwich structure with aluminum alloy and steel sheet

The thermal-chemical-structural coupling numerical model of the curing process is implemented and simulated in finite element analysis software (Version 5.5) COMSOL Multiphysics, which is suitable for solving coupling problems of multi physical field. The modules of Heat Transfer, Partial Differential Equation (PDE) and Solid Mechanics are used to describe the physical fields of heat convection and transfer, adhesive curing and structural deformation respectively. The direct coupling between modules is realized by sharing the temperature and time variables, and the calculation of the numerical model can be achieved by calling the corresponding application module subroutine. The calculation flow of thermal-chemical-structural coupling field of bonded sandwich structure is shown in Fig. 3. In the Heat Transfer module, the 
boundary condition parameters of the model can be set, and the parameters (Table 1,3) related to heat convection and heat transfer of different materials can be defined. In the PDE module, the general form of coefficient partial differential equation is:

$$
e_{a} \frac{\partial^{2} u}{\partial t^{2}}+d_{a} \frac{\partial u}{\partial t}+\nabla \cdot(-c \nabla u-\alpha u+\gamma)+\beta \cdot \nabla u+a u=f
$$

where $u$ and $t$ are the dependent variable and time respectively, $f$ is the source form. $c, a$, $e_{\mathrm{a}}, d_{\mathrm{a}}, \alpha, \beta$ and $\gamma$ are the undetermined coefficients. By modifying the coefficients and the source term parameters (Table 1), the formula. (15) is transformed into the curing kinetics Eq. (3). In the Solid Mechanics module, the mechanical material parameters (Table 1,3) of different materials, such as bulk modulus, shear modulus and relaxation time (Table 2), can be defined.

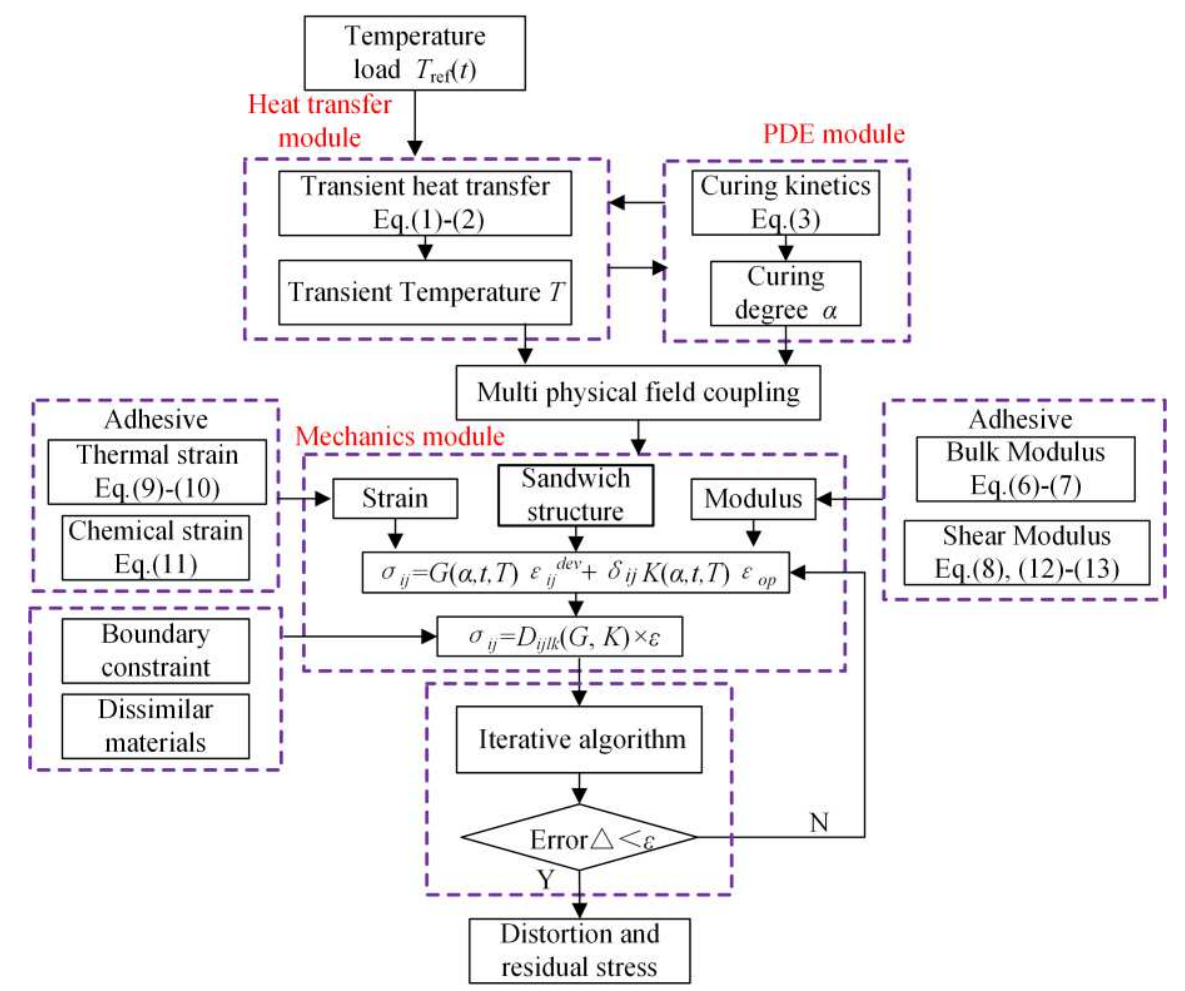

Fig. 3 Calculation process of thermal-chemical-structural coupling field of bonded sandwich structure in COMSOL Multiphysics

The adhesive at the corner is divided into a triangular prism mesh with a minimum size of $0.05 \mathrm{~mm}$, and the rest of the structure is divided into a hexahedral mesh as 
shown in Fig. 4. Along the $x$ direction, the mesh of the structure is evenly divided, and the size of $2 \mathrm{~mm}$. Along the $y$ direction, the mesh size at the flanged part is relatively dense, which is $0.5 \mathrm{~mm}$, while the mesh in other areas is relatively sparse. To improve the calculation accuracy, the quadratic Lagrangian element is used. In the temperature field, the air convection boundary condition is applied to the surface of the structure. In the structural field, the ends of the structure are fixed and other regions are unconstrained. Corresponding to the multi stages of the constitutive model, the numerical calculation is carried out in stages and the transient time domain method is used.

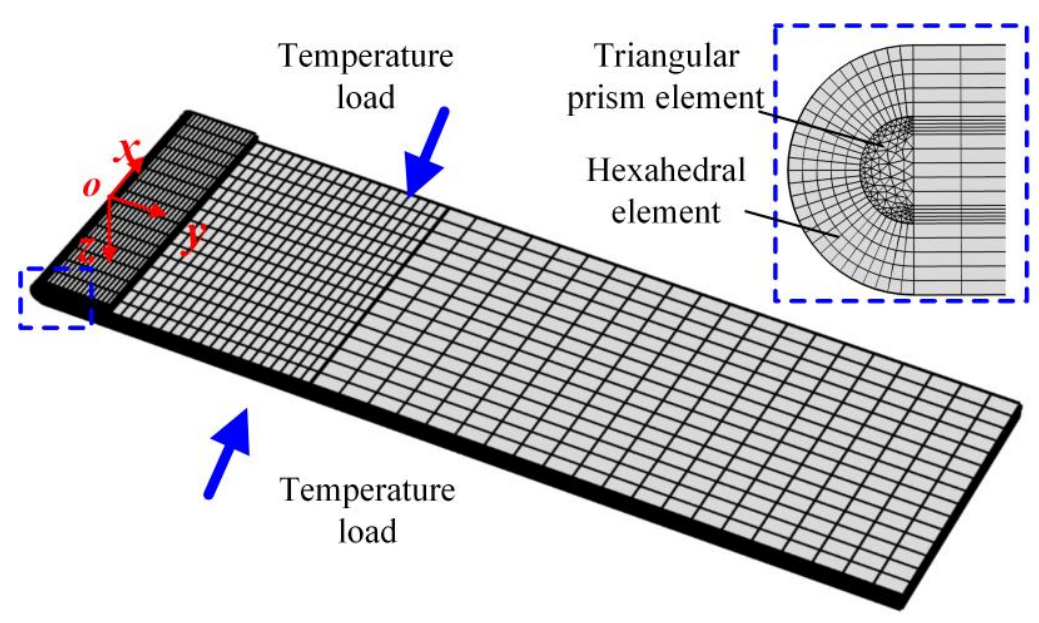

Fig. 4 Finite element mesh of adhesively bonded sandwich structure with aluminum alloy and steel sheet

\subsection{Verification Experiment based on DIC}

In the baking environment, the adhesive layer is sandwiched between the inner and outer panels. As the deformation is dynamic, it increases the difficulty of direct gauging. When traditional strain gauge is used to measure the stain data of the adhesive layer in contact, the deformation accuracy of the sample is easily affected. Thus, indirect quantification of non-contact measurement becomes the best verification method [11]. To avoid the limitations of single point position measurement and record the full-field dynamic deformation of aluminum alloy outer panel, the DIC method is adopted, which 
is widely used in the deformation field of non-contact measurement [27].

(a)

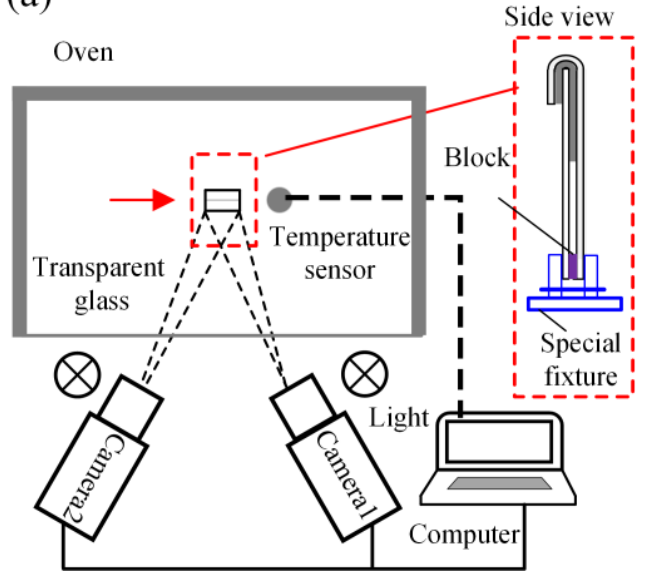

(b)

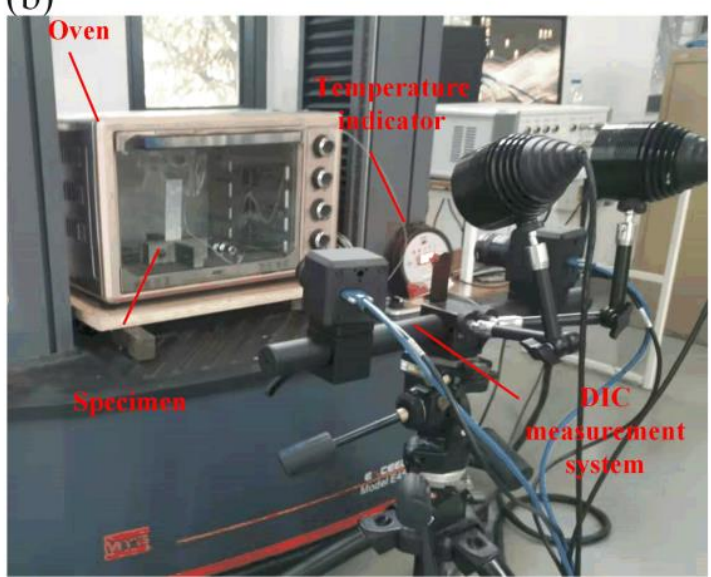

Fig. 5 Curing-induced distortion measurement experiment. a Non-invasive measurement schematic diagram. b Measurement device based on DIC technology

The experimental principle and device are shown in Fig. 5. The measurement system mainly includes: DIC device XTDIC (XTOP, China), oven and high temperature sensor. The cameras of the measurement device have 10 million pixels and the dynamic displacement identification accuracy of the system is $0.05 \mathrm{~mm}$. The outer surface of the specimen is sprayed with speckle paint for system identification. $0.2 \mathrm{~mm}$ steel block is added in the middle of the sample end to control the thickness of the adhesive layer, as shown in Fig. 5a. Meanwhile, the length of the sample in the experiment is $10 \mathrm{~mm}$ longer than that of the simulation, and the extra $10 \mathrm{~mm}$ is used for clamping. Then, the sample is fixed by fixture, and placed on the refractory brick in the oven. The heating temperature cycle which is described in Section 3.1 is controlled by the oven, and the deformation results are recorded by the cameras. Finally, the data are compared and analyzed by DIC system. Each experiment is conducted three times and the average value is taken.

\section{Results and discussion}

\subsection{Comparison of methods}


For the convenience of comparison, the beginning of temperature cooling is defined as initial point $(\mathrm{t}=0 \mathrm{~min})$ by time equivalent conversion. Since surface quality is the focus of the sandwich structure, Fig. 6 shows the curing-induced deformation values in the $z$ direction (Fig .4). It can be seen that the surface displacement values obtained by the experiment and the simulation are basically consistent, and the deformation trend is in good agreement. Because the width value is small, the deformation of the aluminum alloy panel changes little along the $y$ direction. Therefore, in the case of large length-width ratio, the deformation of the sandwich structure is approximately regarded as a plane strain problem. In general, under the temperature cycle, the component first bends along the negative direction of the $z$-axis, then gradually stabilizes, and finally bends in the positive direction of the $z$-axis. The results show that the deformation process can be simulated well based on the multi-physics coupling model.
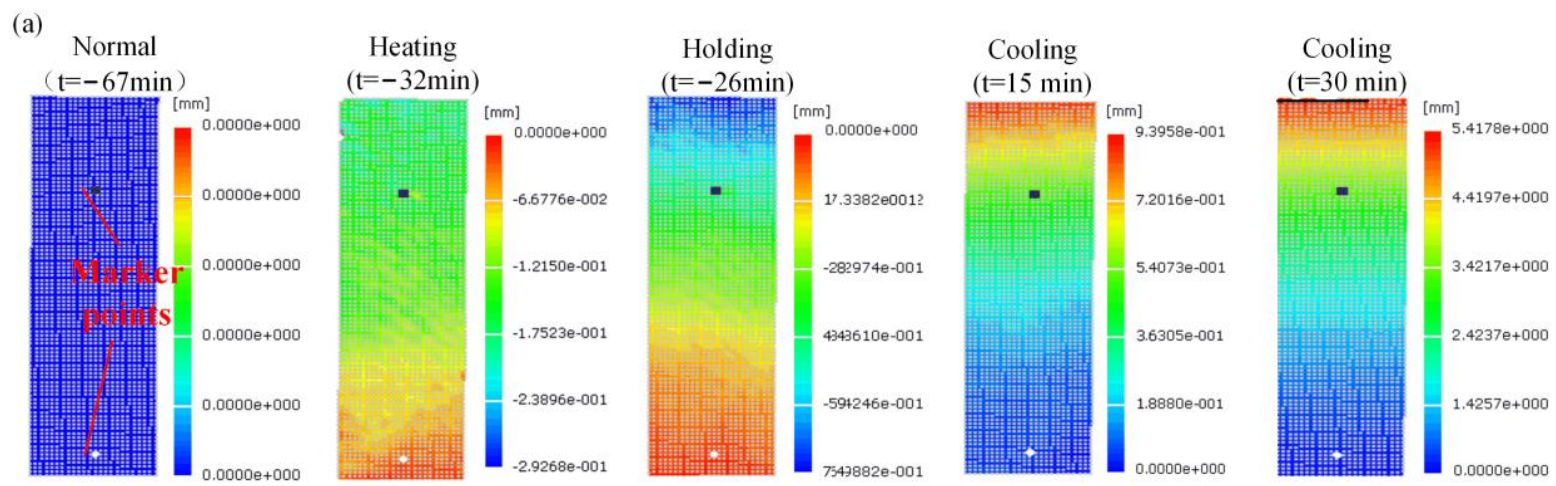

(b)
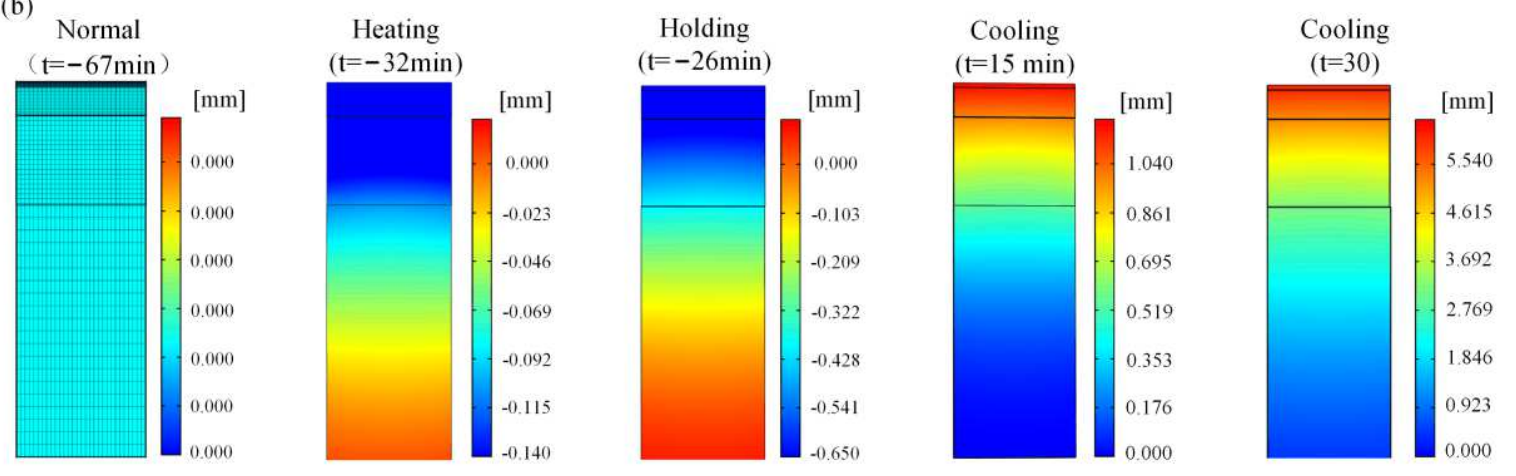

Fig. 6 Evolution of curing-induced surface deformation of bonded sandwich structure in different temperature stages. a Measured by DIC experiment (One of the samples). b Simulation based on multi-field coupling model. 
As the deformation value is the largest and can reflect the degree of the structural deformation, the M-point (Fig .2) on the middle section is selected as the comparison point. Fig. 7a shows the transient variation process of M-point on the middle section obtained by using different methods. It can be seen that the curing-induced structural displacement does not start at the beginning of heating. When the molecular crosslinking reaches a certain degree, M-point begins to move in the negative direction of the z-axis. After reaching the holding temperature, the deformation begins to rebound slightly, and then enters a stable state, which is related to the curing shrinkage. Finally, with temperature cooling down, the point begins to warp in the positive direction of the z-axis. At the beginning of the cooling stage, the deformation speed of the structure is relatively slower, which is related to the faster stress relaxation of the adhesive. Fig. $7 \mathrm{~b}$ shows the final z-axis displacement of the outer contour of the middle section. It can be seen that the traditional viscoelastic models $[9,11]$ have a relatively large deviation from the results, which ignores the change of material properties. The multi-physics coupled model well reflect the changing process.
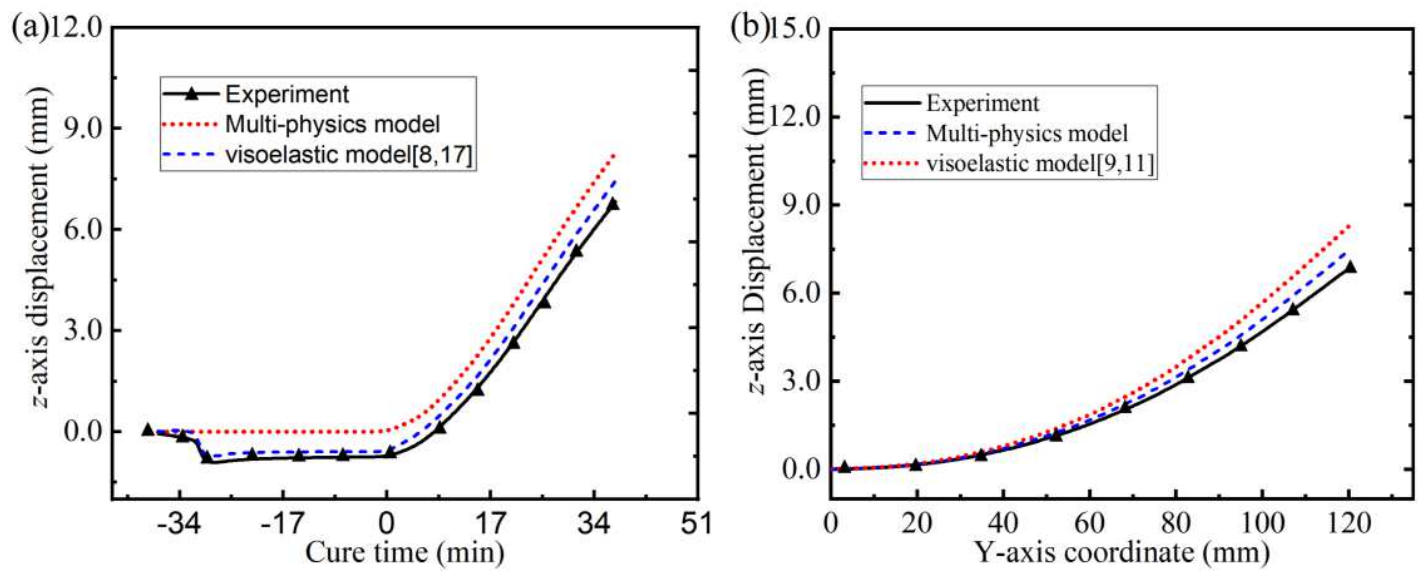

Fig. $7 \mathrm{Z}$-axis displacement variation on the middle section obtained by different methods. a Displacement variation of M-point with time. b Final $z$-axis displacement of the middle section

\subsection{Deformation process of the sandwich structure}

Fig. 8 shows the physical fields of the adhesive at different curing stages. It can be seen 
that the temperature almost does not change along the $x$ direction. In the heating stage, the temperature at the corner is slightly lower than that in other regions along the $y$ direction, which is related to the heat transfer. In the high holding stage, the temperature is about $1 \sim 2{ }^{\circ} \mathrm{C}$ higher at the corner than that in other regions, which is related to the exothermic of the adhesive. In the heating and holding stage, the curing field is similar to the temperature field, and the difference is relatively small in different areas. In the structural field, the von Mises stress on both sides is relatively large, especially in the cooling stage, which is mainly related to the boundary constraints.
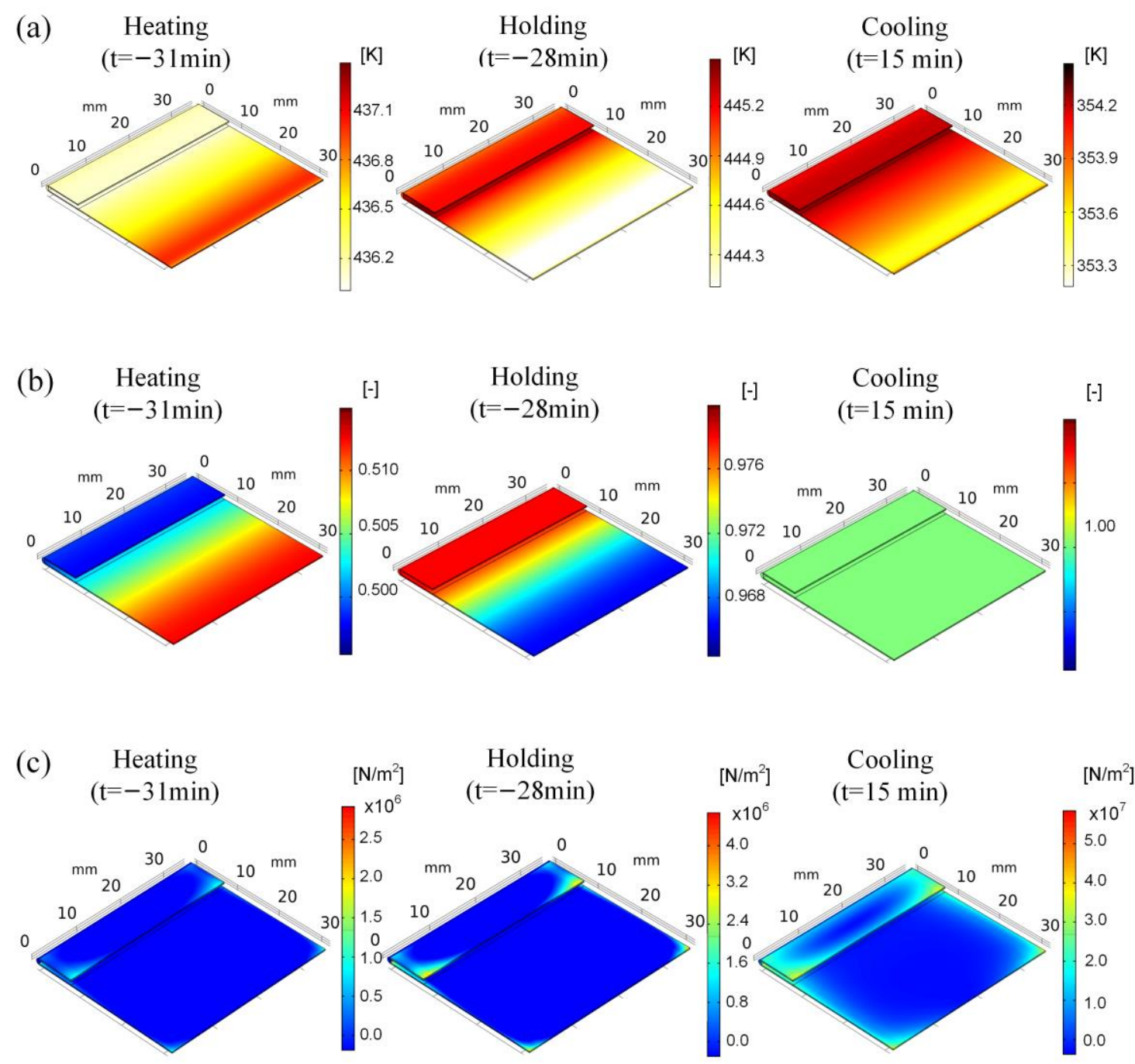

Fig. 8 Physical fields of the adhesive at different curing stages. a Temperature field. b Curing degree field. c Von Mises stress field

Fig. 9 shows the development of temperature and curing degree distribution of the 
adhesive layer in the $y z$ plane. It can be seen that the maximum difference in different regions of the adhesive layer is about $1 \sim 2{ }^{\circ} \mathrm{C}$. This is due to the high thermal conductivity of the panels and the relatively thin thickness of the adhesive layer, which results in no delaying and obvious gradient change. After heating up, the temperature continued to rise slightly due to the exothermic reaction of the adhesive. Accordingly, under the same external temperature environment, the change of the curing degree of each position has almost the same.

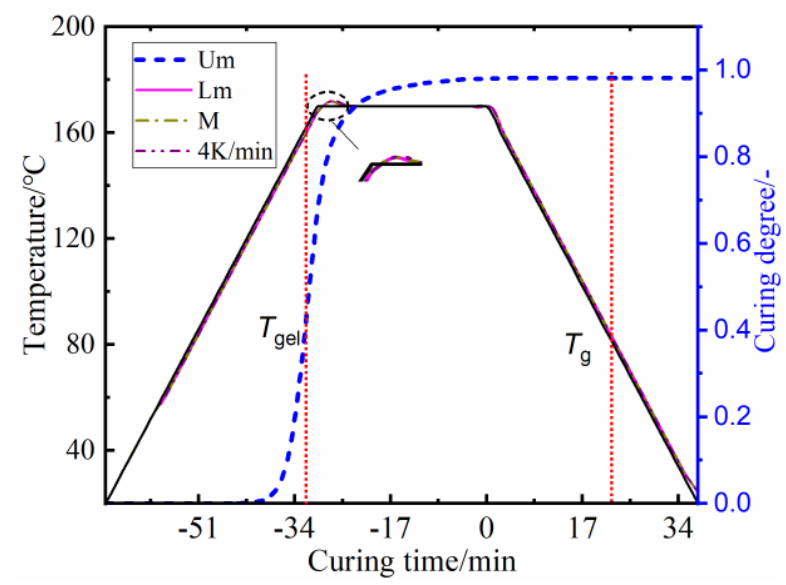

Fig. 9 Evolution of temperature and curing degree of the adhesive layer

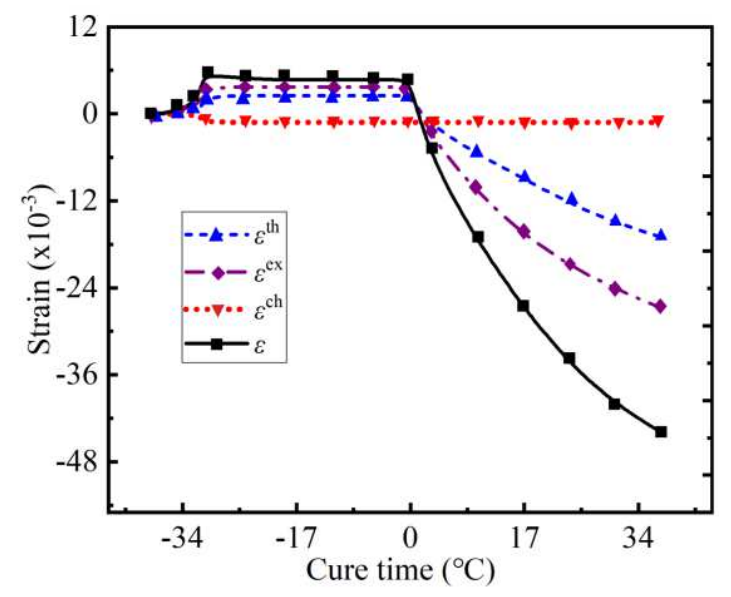

Fig. 10 Evolution of strain at point Um under temperature cycle

Fig. 10 shows the evolution of different strains $\varepsilon_{z z}$ in $\mathrm{z}$ direction at point $\mathrm{U}_{\mathrm{m}}$ (Fig. 2) of adhesive layer. When the temperature exceeds $T_{\text {gel }}$, the bonding strength at the interface is gradually established between the adhesive and the panels. Since the CTE of 
aluminum alloy is larger than that of steel, relative dislocation movement occurs [7]. Compared with other structures, such as bimaterial [10] and bonded substructure [14], mechanical strain caused by the difference of material properties plays an important role. At the beginning of the phase II, the influence of thermal expansion strain and mechanical strain on deformation is greater than that of chemical shrinkage. After reaching the maximum temperature $170^{\circ} \mathrm{C}$, the structure produces a small amount of positive movement along the $z$-axis, which can be explained by continuous curing shrinkage [12], as shown in Fig. 8. In the phase III, the chemical shrinkage gradually stops and remains unchanged. And compared with thermal strain, mechanical strain began to dominate, which cause the structure bend forward along the $z$-axis. In the phase IV, the mechanical strain decreases gradually, due to the increase of the adhesive modulus.
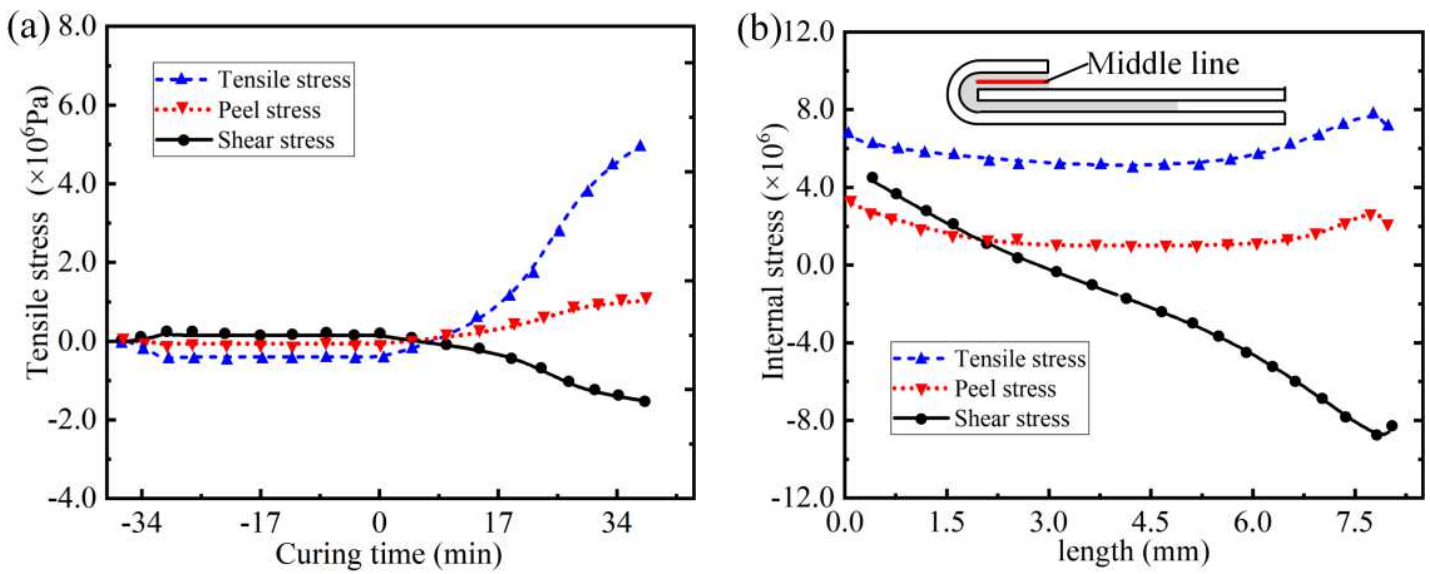

Fig. 11 Variation of internal stress of the upper adhesive layer on the middle section. a Variation of different stresses at point Um. b Final internal stress at the middle line

Fig. 11a shows development of internal stress of the adhesive layer at point Um (Fig. 2) on the middle section. It can be seen that the direction of the internal stress of point-Um, including tensile stress $\sigma_{x x}$, shear stress $\sigma_{x y}$ and peel stress $\sigma_{z z}$, changes with the decrease of the temperature. It shows that the upper adhesive layer is compressed first and then stretched. In phase II of the material constitutive model, due to the relatively low modulus, about tens of $\mathrm{MPa}$, the internal stress value is relatively low. At 
the beginning of phase III, the stress grows slowly with the cooling of temperature, since the stress relaxation is fast. With the glass transition of the adhesive, then the stress increases rapidly. In the phase IV, the stress increases slowly, which is related to the decrease of CTE and stress relaxation. Fig. 11b shows the final internal stress at the middle line of the upper adhesive layer. The tensile and peel stress are slightly larger at the edge, which is related to the boundary constraint. The shear stress direction of the left side and the right side changes, which is related to the asymmetric structure.
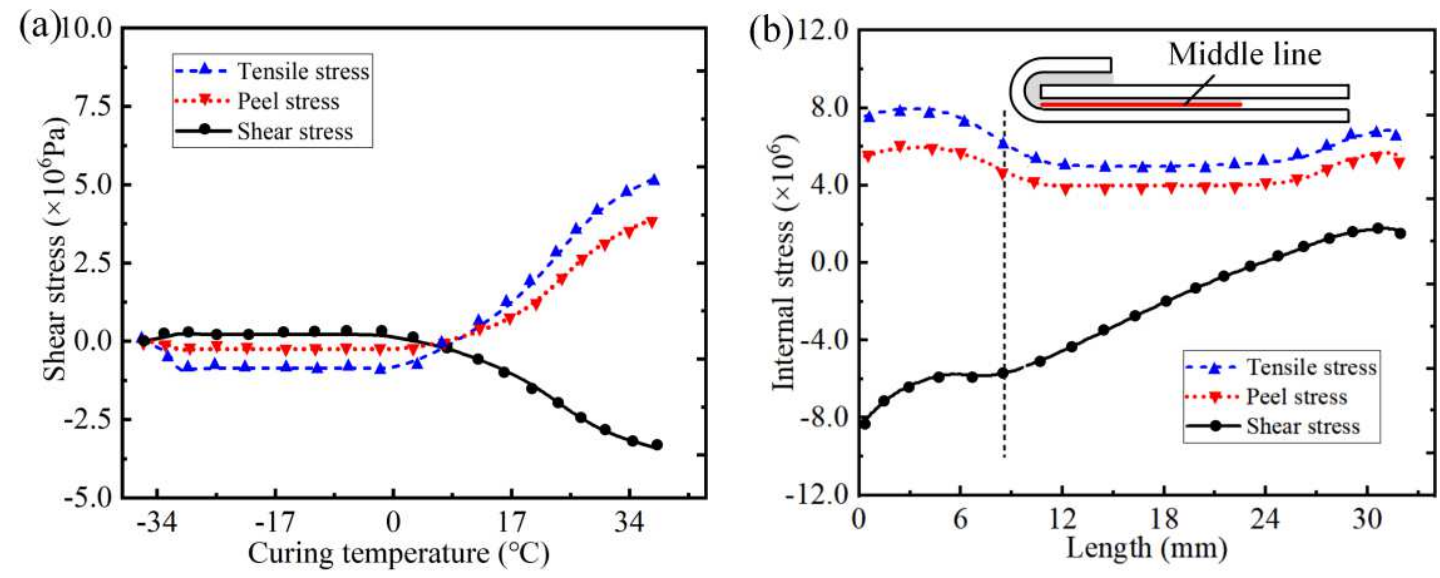

Fig. 12 Variation of internal stress of the upper adhesive layer on middle section. a Variation of different stresses at point Um. b Final internal stress at middle line

Fig. 12a shows development of internal stress of the adhesive layer at point Dm on the middle section. The variation of point Dm is similar to that of point Um. Fig. 12b shows the final internal stress at the middle line of the lower adhesive layer. The stress near the circular corner is relatively large, which is related to the geometric structure.

(a)

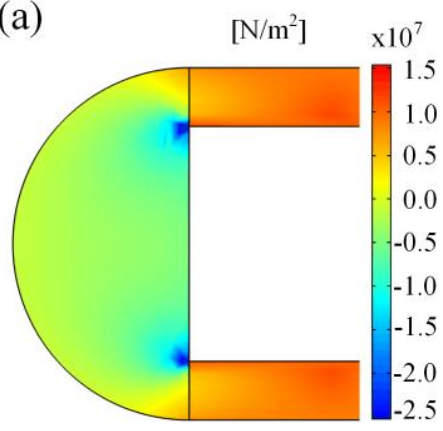

(b)

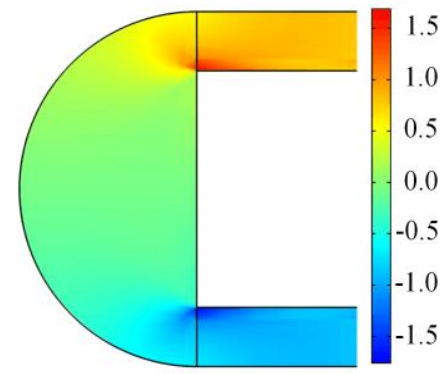

(c)

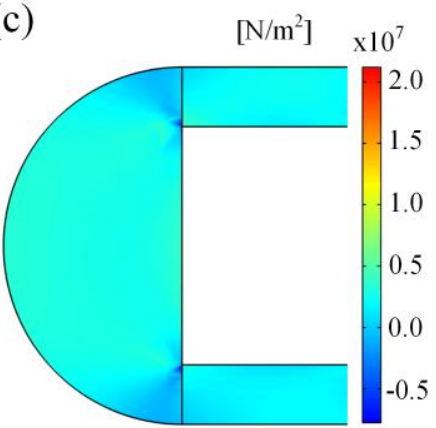


Fig. 13 Final internal stress at the circular corner. a Tensile stress. b Shear stress. c Peel stress

Figure 13 shows the final internal stress at the circular corner. It can be seen that the internal stress changes dramatically, and the stress concentration appears in the right angle region, due to the change of boundary conditions. The tensile and shear stresses at the circular corner are less than those at the upper and lower adhesive layers. The shear stress decreases obviously and becomes zero in the middle region.

\subsection{Influence of curing temperature cycles}

Fig. 14a shows the maximum displacement of the outer panel at $170{ }^{\circ} \mathrm{C}$ under different heating rates. It can be seen that the predicted value of the model is still in good agreement with the experimental results, when the heating conditions change. The results show that the final deformation of the structure can be reduced by reducing the curing rate. This is due to the heating rate affects the gel point and the bonding temperature between the adhesive and the panels [5, 12]. Fig. 14b shows the curing degree curves of the adhesive under different heating rates. When the heating rate decreases, the curing curve moves to the left, which leads to lower gel temperature. On the contrary, the higher the heating rate, the higher the gel temperature. When the heating rate exceeds a certain value, as the $8 \mathrm{~K} / \mathrm{min}$, the adhesive is bonded to the panels in the heat holding stage, and the overall deformation value is the maximum [13].
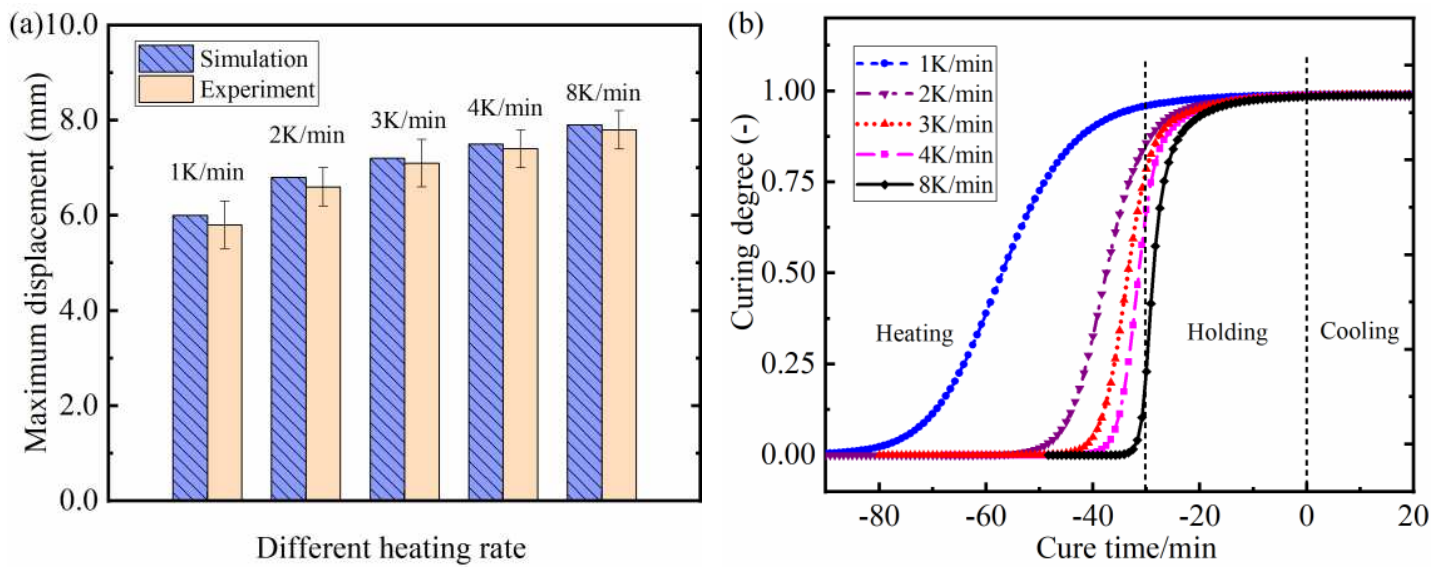

Fig. 14 Maximum displacement and curing degree curves at holding temperature $170{ }^{\circ} \mathrm{C}$. a Maximum displacement under different heating rates. b Curing degree curves 
Fig. 15a shows the maximum displacement of the outer panel at $150{ }^{\circ} \mathrm{C}$ under different heating rates. It can be seen that the final deformation at $150{ }^{\circ} \mathrm{C}$ is significantly lower than that at $170{ }^{\circ} \mathrm{C}$. This is because the decrease of the maximum temperature reduces the gel temperature of adhesive, and reduces the temperature difference of cold contraction deformation between aluminum alloy and steel panels. Under the condition of 3, 4 and $8 \mathrm{~K} / \mathrm{min}$, the deformation value is almost the same, which is related to gel in the holding stage, as shown in Fig. 15b. The curing curves moves to the right, compared with the temperature condition of $170{ }^{\circ} \mathrm{C}$. This makes the samples under the condition of 3, 4 and $8 \mathrm{~K} / \mathrm{min}$ all gel and cure during the holding stage. When dissimilar materials used, the difference of material properties makes the deformation always exist. Adjusting the curing kinetics characteristics of the adhesive layer can reduce the structural deformation, but it may prolong the curing time.
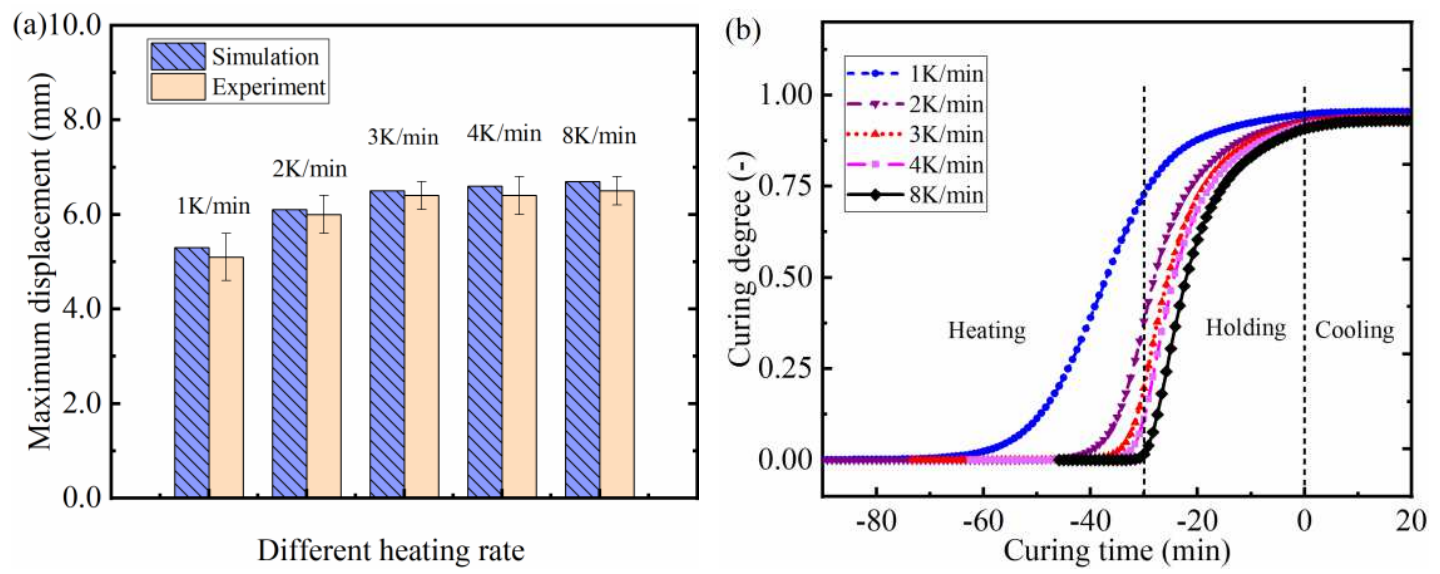

Fig. 15 Maximum displacement and curing degree curves at holding temperature $150{ }^{\circ} \mathrm{C}$. a Maximum displacement under different heating rates. b Curing degree curves

\section{Conclusion}

A multi-physics coupling numerical model of the curing process was proposed to study the residual internal stress and deformation of the adhesively bonded sandwich structure of dissimilar materials. The simulation prediction accuracy is verified by experiments. Then, the development process of surface deformation of the outer panel and internal stress of the adhesive layer is analyzed, and the influence of temperature cycle on the 
maximum deformation of the component is discussed. Several conclusions can be drawn:

1). Compared with the traditional viscoelastic model, the multi-physics coupled model has higher prediction accuracy and can better reflect the deformation process of the structure, due to considering the change of adhesive material properties.

2). At the beginning of the holding stage, the deformed component slightly rebounds, which is related to the chemical shrinkage. At the beginning of the cooling stage, the deformation rate is relatively slow, which is related to the faster stress relaxation of the adhesive.

3). The temperature difference in different areas of the adhesive layer is relatively small, about $1 \sim 2{ }^{\circ} \mathrm{C}$, and the difference of the curing degree is less than 0.01 , due to the high thermal conductivity of the panels and the thin thickness of the adhesive layer.

4). Compared with other structures, such as bimaterial [10] and bonded substructure [14], mechanical strain caused by the CTE and stiffness difference of inner and outer panels is dominant. The direction and size of shear stress in the upper and lower adhesive layers change along the y-axis, which is related to asymmetric structure.

5). When the gel temperature is the maximum holding temperature, the overall deformation reaches the maximum. Reducing the curing rate and maximum holding temperature is helpful to reduce the overall deformation, as it reduces the gel temperature of the components.

\section{Declarations}

\section{Funding}

This research was supported by the NSFC-China (National Natural Science Foundation of China) Project (No.51975416 and No.51275359).

\section{Conflicts of interest/Competing interests}

The authors declare that they have no known competing financial interests or personal relationships that could have appeared to influence the work reported in this paper. 


\section{Availability of data and material}

The raw/processed data are available from the corresponding author on reasonable request.

\section{Code availability}

The software application/custom code are available from the corresponding author on reasonable request.

\section{References}

1. Martinsen K, Hu SJ, Carlson BE (2015) Joining of dissimilar materials. Cirp Ann-Manuf Tech 62:679-699 https://doi.org/10.1016/j.cirp.2015.05.006

2. Baneaa MD, Rosioarab M, Carbasb RJC, Silva LFM (2018) Multi-material adhesive joints for automotive industry. Compos Part B-Eng 151:71-77

https://doi.org/ 10.1016/j.compositesb.2018.06.009

3. Hu P, Han X, Li W, Shi Z, Zhou S (2012) Influence of automobile body coating process on the strength of unbalanced adhesive joints. Chin J Mech Eng 48(20):93-102 https://doi.org/10.3901/JME.2012.20.093

4. Hu X, Zhao YX, Huang S, Li SH, Lin ZQ (2012) Numerical analysis of the roller hemming process. Int J Adv Manuf Technol 62(5-8):543-550 https://doi.org/10.1007/s00170-011-3822-4

5. Hahn O, Jendrny J (2003) Evaluation of simulation models for the estimation of deformation of adhesively bonded steel sheets during curing. Weld World 47:31-38 https://doi.org/10.1007/BF03266392

6. Zhu X, Li Y, Chen G, Wang P (2013) Curing-induced distortion mechanism in adhesive bonding of aluminum aa6061-t6 and steels. J Manuf Sci E-T ASME 135:051007 https://doi.org/10.1115/1.4025013

7. Silva LFMD, Adams RD (2007) Adhesive joints at high and low temperatures using similar and dissimilar adherends and dual adhesives. Int J Adhes Adhes 27:216-226 https://doi.org/10.1016/j.ijadhadh.2006.04.002

7. Liu W, Zhu X, Zhou Q, He H, Liu J, Xu C, Li L (2020) Modeling and simulation of the flow drill 
screw process of a DP590/A16061-T6 multi-material joint used for vehicle body. Int J Adv Manuf Tech 110:1189-1201 https://doi.org/10.1007/s00170-020-05909-3

8. Xin W, Hao H, Zhang G, Cindy R (1999) Variation in autobody adhesive curing process. SAE Tech 01:0997 https://doi.org/10.4271/1999-01-0997

9. Basu SK, Kia HG (2008) Theoretical modeling of bond-line read-out in adhesive joined SMC automotive body panels. J Compos Mater 42:539-552 https://doi.org/10.1177/0021998307088604

10. Patankar KA, Dillard DA, Fernholz KD (2013) Characterizing the constitutive properties and developing a stress model for adhesive bond-line readout. Int J Adhes Adhes 40:149-157 https://doi.org/10.1016/j.jiadhadh.2012.07.006

11. Fuchs H, Fernholz KD, Deslauriers P (2010) Predicted and measured bond-line read-through response in composite automotive body panels subjected to elevated temperature cure. J Adhesion 86:982-1011 https://doi.org/10.1080/00218464.2010.515471

12. Priesnitz K, Sinke J, Benedictus R (2014) Influence of the temperature cycle on local distortions in car panels caused by hot curing epoxies. Int J Adhes Adhes 50:216-222

https://doi.org/10.1016/j.jjadhadh.2014.01.035

13. Cho J, Sun CT (2003) Modeling thermal residual stresses in composite patch repairs during multi temperature bonding cycle. J Aircraft 40:1200-1204 https://doi.org/10.2514/2.7211

14. Konstantin P, Jos S, Rinze B (2014) On the simulation of panel distortions due to hot curing adhesives. Int J Solids Struct 51:2470-2478 https://doi.org/10.1016/j.ijsolstr.2014.03.016

15. Jansen KMB, Vreugd J, Ernst LJ (2012) Analytical Estimate for curing-induced stress and warpage in coating layers. J Appl Polym Sci 126:1623-1630 https://doi.org/10.1002/app.36776

16. Vreugd J (2011) The effect of aging on molding compound properties. Dissertation, Delft University of Technology

17. Vreugd J, Jansen KMB, Ernst LJ, Bohm C (2010) Prediction of cure induced warpage of micro-electronic products. Microelectron. Reliab 50(7):910-916

https://doi.org/10.1016/j.microrel.2010.02.028

18. Yan X (2010) Fintie element modeling of curing of epoxy matrix composites. J Appl Polym Sci 103(4):2310-2319 https://doi.org/10.1002/app.24337

19. Li D, Li X, Dai J (2018) Process modelling of curing process-induced internal stress and deformation of composite laminate structure with elastic and viscoelastic models. Appl Compos 
Mater 25:527-544 https://doi.org/10.1007/s10443-017-9633-5

20. Kissinger, HE (1957) Reaction kinetics in differential thermal analysis. Anal Chem 29:1702-1706

21. Málek J (1992) The kinetic analysis of non-isothermal data. Thermochim Acta 200:257-269 https://doi.org/10.1016/0040-6031(92)85118-F

22. Ernst LJ, Hof C, Yang D, Kiasat MS, Zhang GQ, Bressers HJL, Caers JFJ, Boer AWJ, Janssen J (2002) Mechanical modeling and characterization of the curing process of underfill materials. J Electron Packaging 124:97-105 https://doi.org/10.1115/1.1459471

23. Yang DG, Jansen KMB, Ernst LJ, Zhang GQ, Janssen JHJ (2007) Effect of filler concentration of rubbery shear and bulk modulus of molding compounds. Microelectron Reliab 47:233-239 https://doi.org/10.1016/j.microrel.2006.09.031

24. Li YG, Mahmood SH, Park CB (2016) Visualization for measuring the PVT property of viscoelastic polystyrene/CO2 mixtures at elevated temperatures and pressures. Polym Test 55:88-96 https://doi.org/10.1016/j.polymertesting.2016.08.010

25. Zarrell M, Skordo A, Partridge IK (2002) Investigation of cure induced shrinkage in unreinforced epoxy resin. Plast Rubber Compos 31:377-384

https://doi.org/10.1179/146580102225006350

26. Senum GI, Yang RT (1977) Rational approximations of the integral of the Arrhenius function. J Therm Anal Calorim 11: 445-447 https://doi.org/10.1007/BF01903696

27. Ke L, Li C, He J, Dong S, Chen C, Jiao Y (2020) Effects of elevated temperatures on mechanical behavior of epoxy adhesives and CFRP-steel hybrid joints. Compos Struct 235:111789 https://doi.org/10.1016/j.compstruct.2019.111789 
Figures

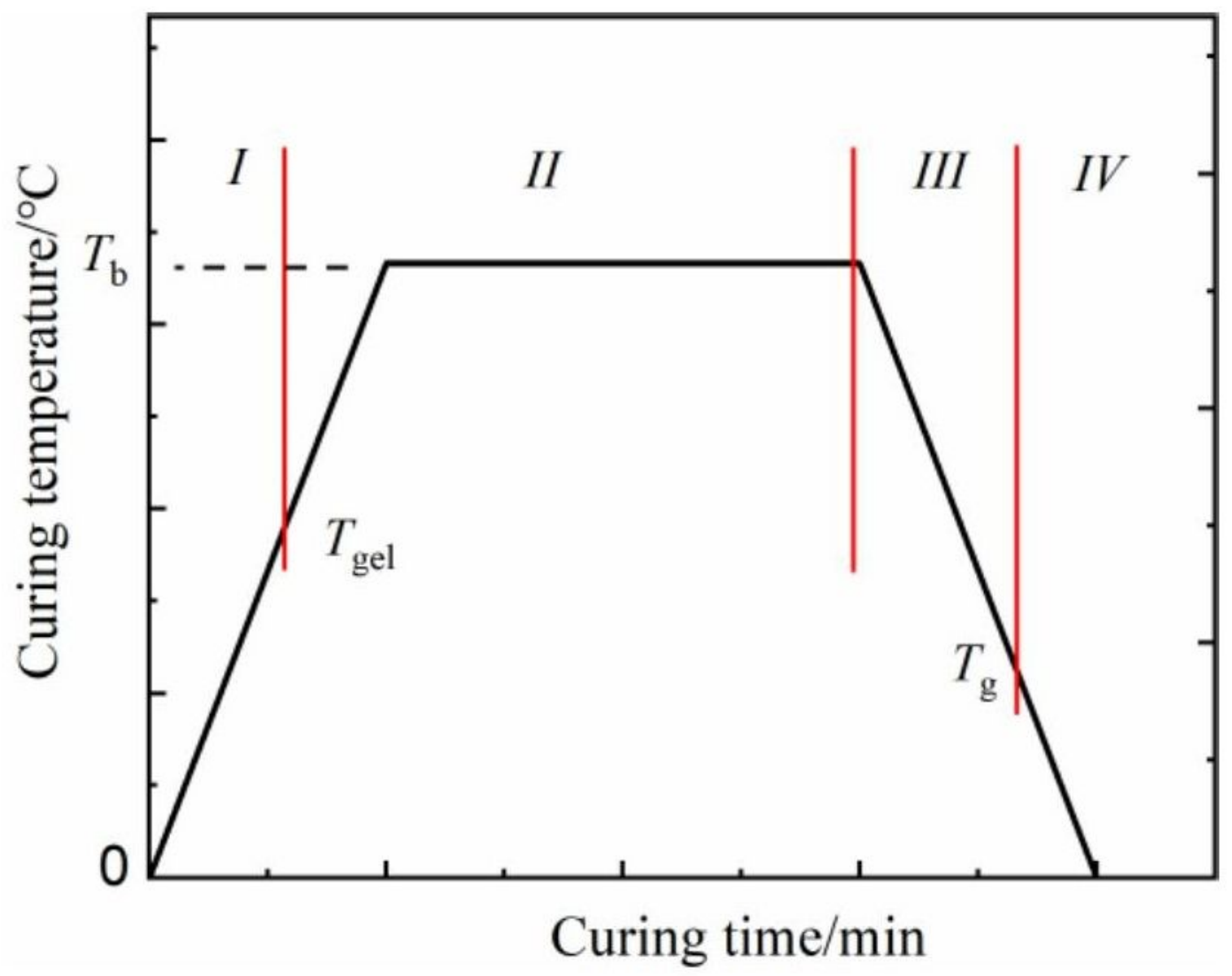

Figure 1

Diagram of four-phase curing model of the adhesive under temperature cycle 


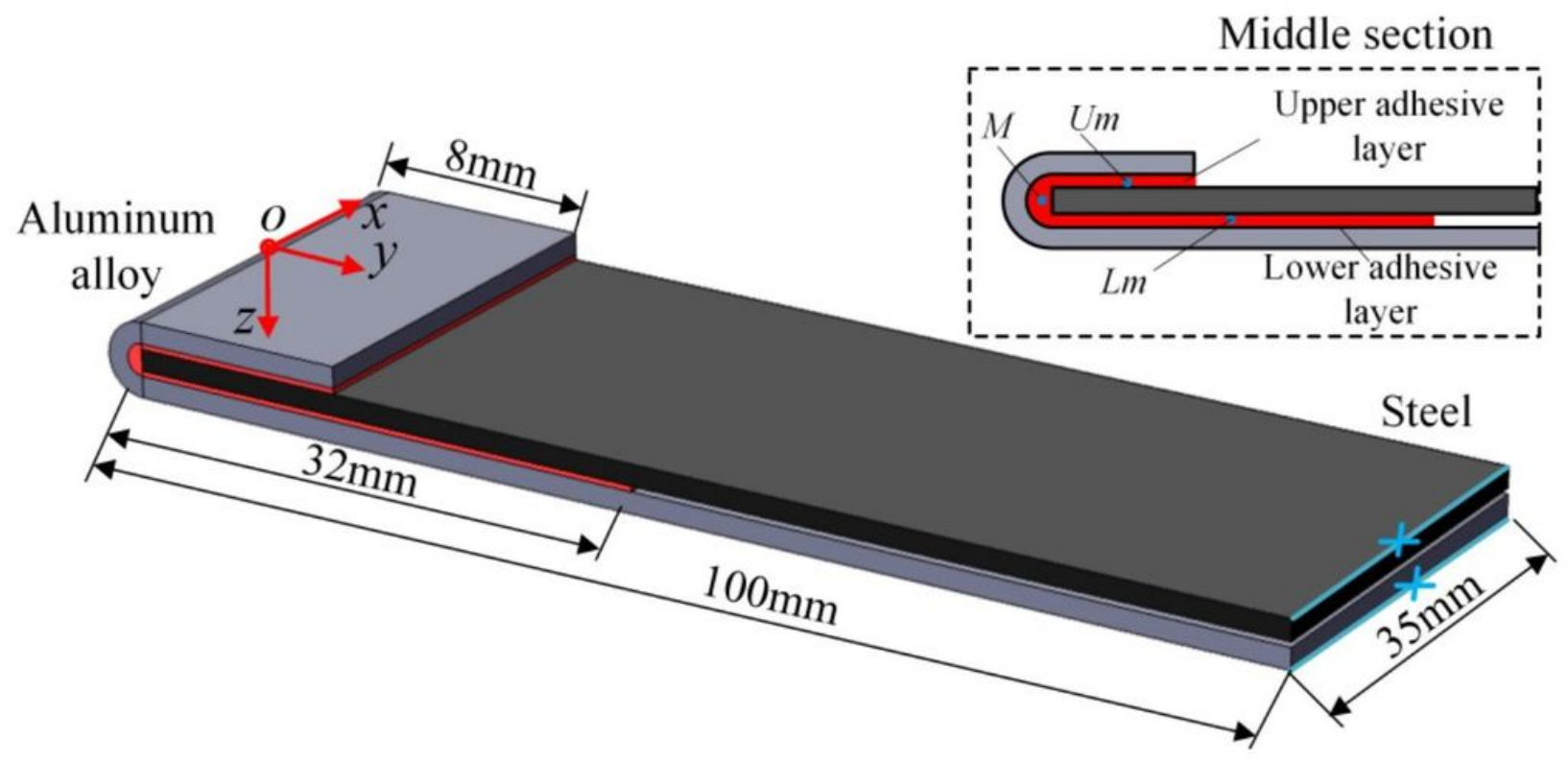

Figure 2

Geometric dimensions of adhesively bonded sandwich structure with aluminum alloy and steel sheet 


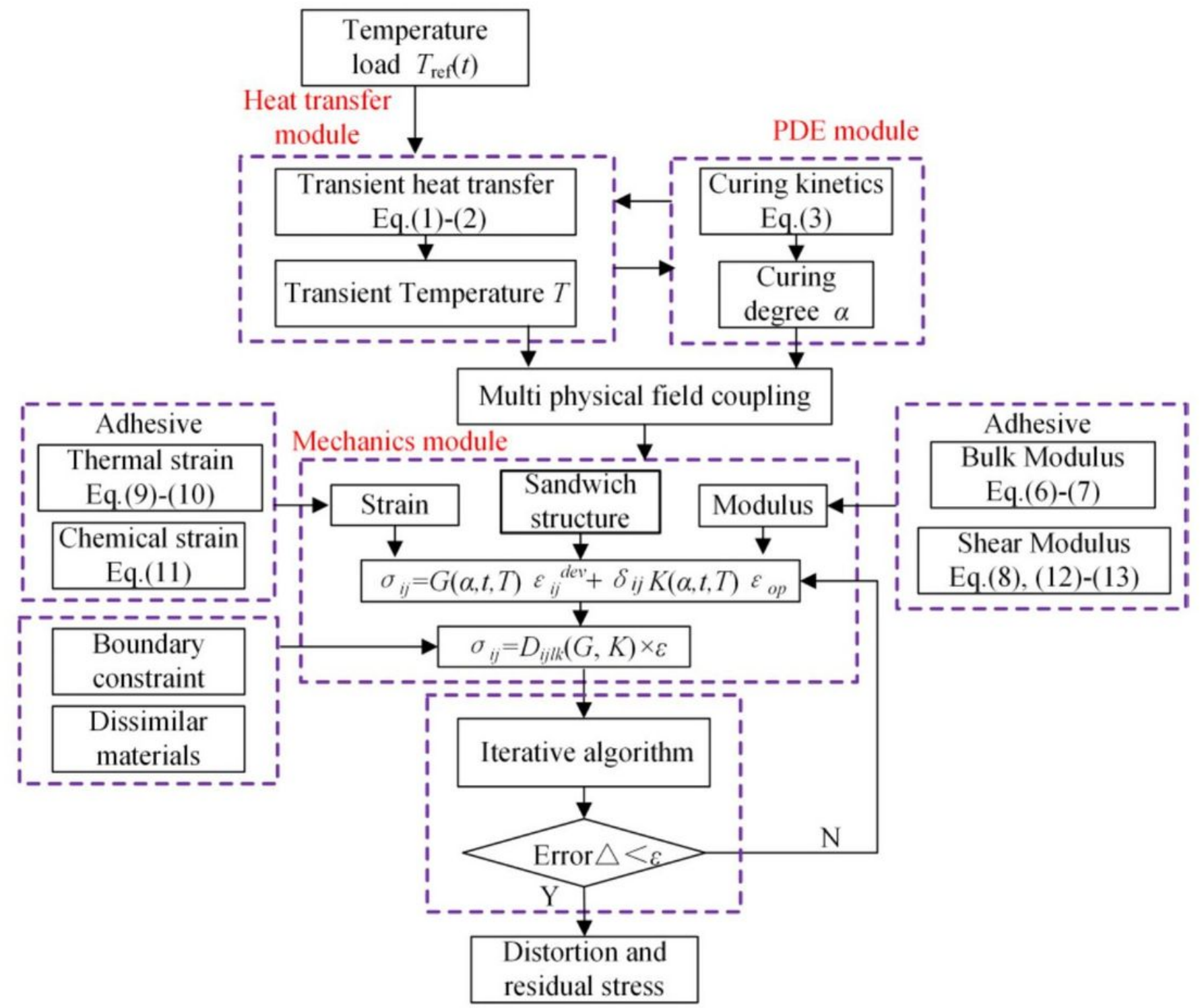

Figure 3

Calculation process of thermal-chemical-structural coupling field of bonded sandwich structure in COMSOL Multiphysics 


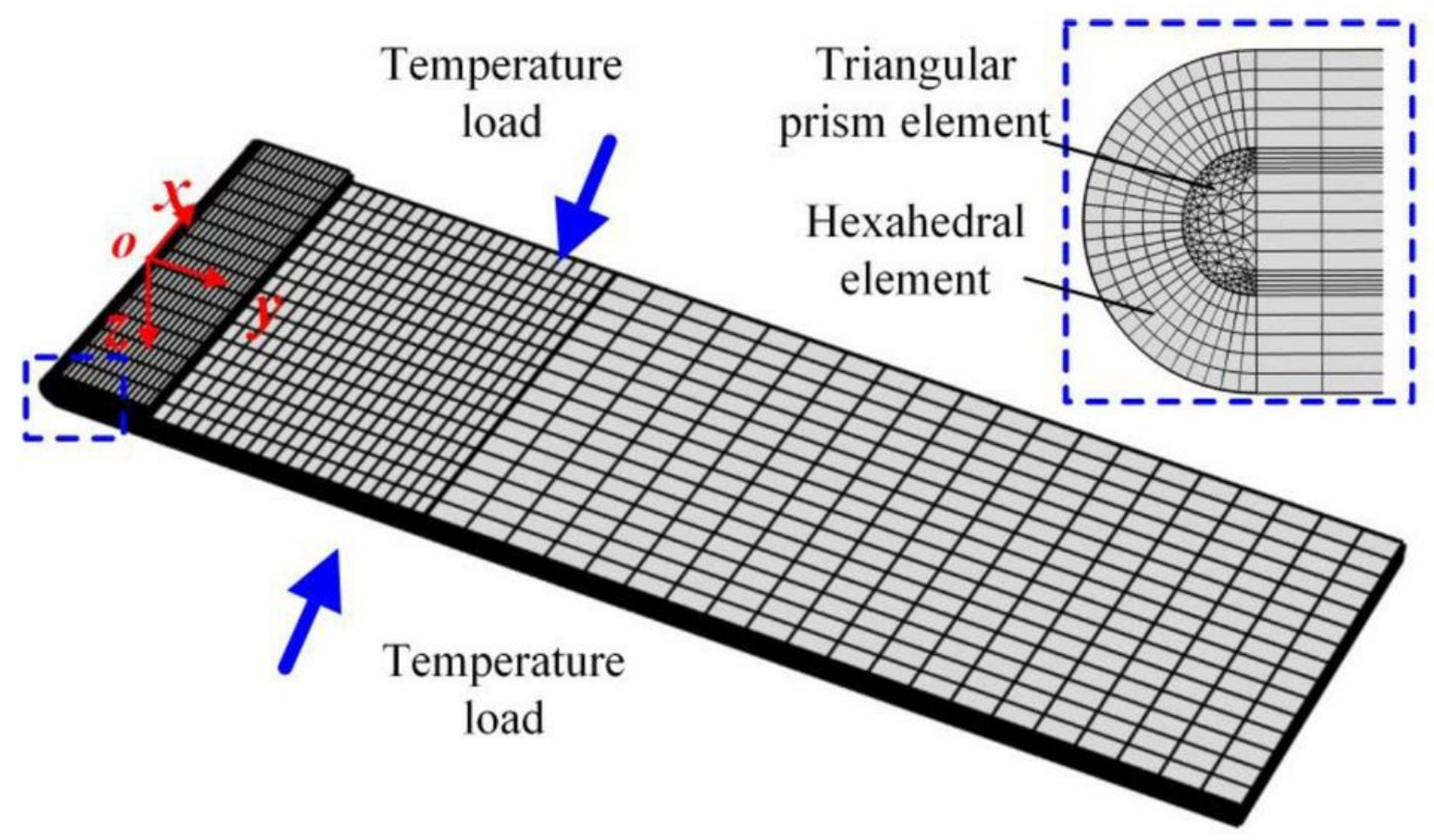

Figure 4

Finite element mesh of adhesively bonded sandwich structure with aluminum alloy and steel sheet

(a)

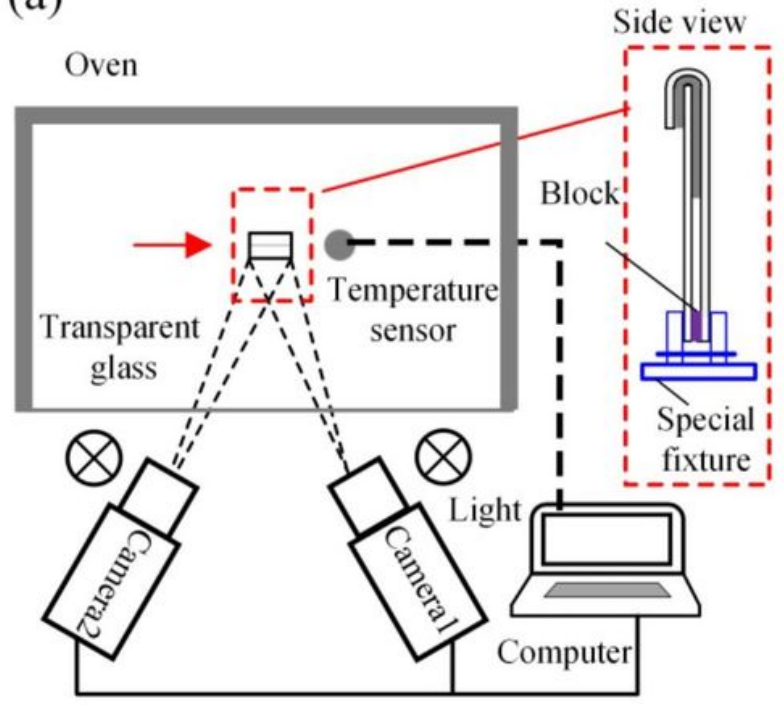

(b)

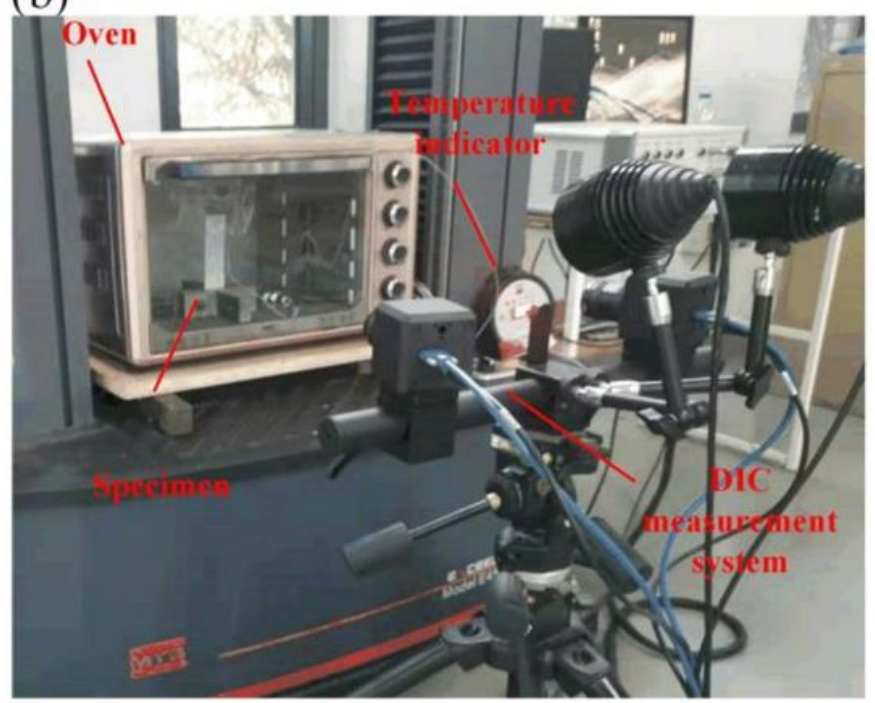

Figure 5

Curing-induced distortion measurement experiment. a Non-invasive measurement schematic diagram. $b$ Measurement device based on DIC technology 
(a)

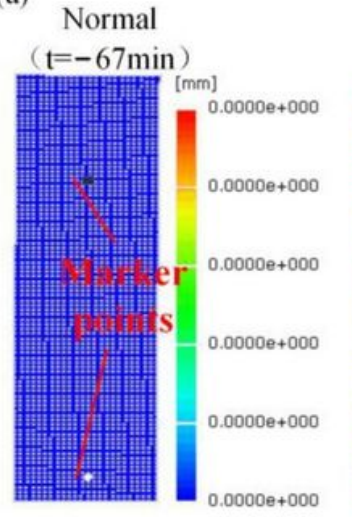

(b)

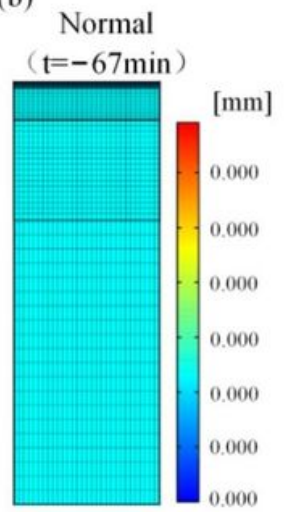

Heating

$(\mathrm{t}=-32 \mathrm{~min})$

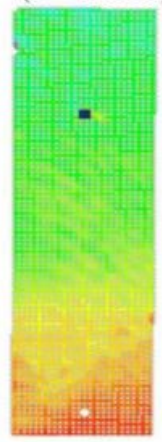

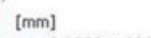

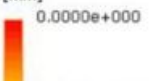

$-6.6776 \mathrm{e}-002$

$-1.2150 e-001$

$-1.7523 e-001$

$-2.3896 \mathrm{e}-001$

$-2.9268 \mathrm{e}-001$
Heating

$(\mathrm{t}=-32 \mathrm{~min})$

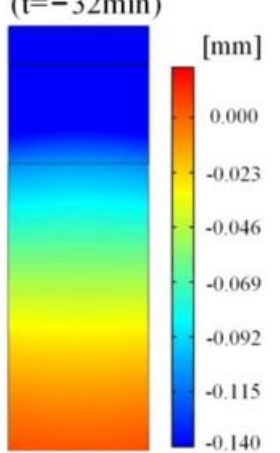

Holding

$(\mathrm{t}=-26 \mathrm{~min})$

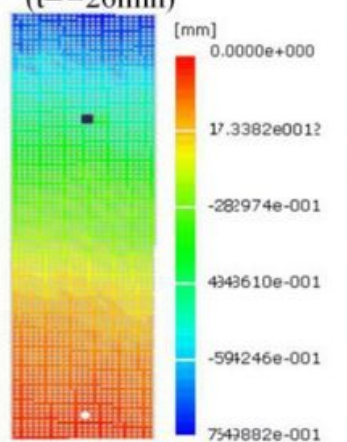

7547882e-001

Cooling

$(\mathrm{t}=15 \mathrm{~min})$

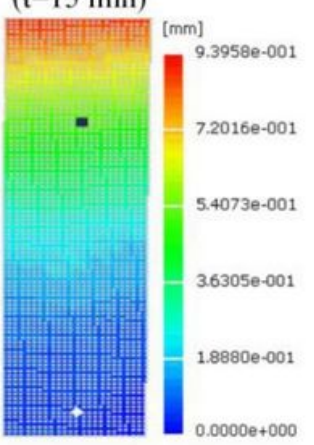

Cooling

$(\mathrm{t}=15 \mathrm{~min})$

$(\mathrm{t}=-26 \mathrm{~min})$

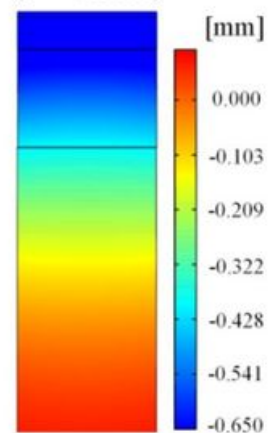

Cooling

$(\mathrm{t}=30 \mathrm{~min})$

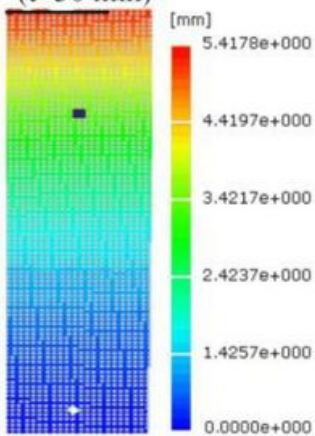

Cooling

$(\mathrm{t}=30)$

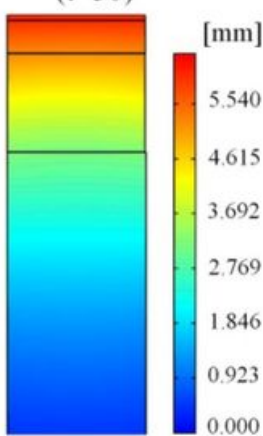

\section{Figure 6}

Evolution of curing-induced surface deformation of bonded sandwich structure in different temperature stages. a Measured by DIC experiment (One of the samples). b Simulation based on multi-field coupling model.
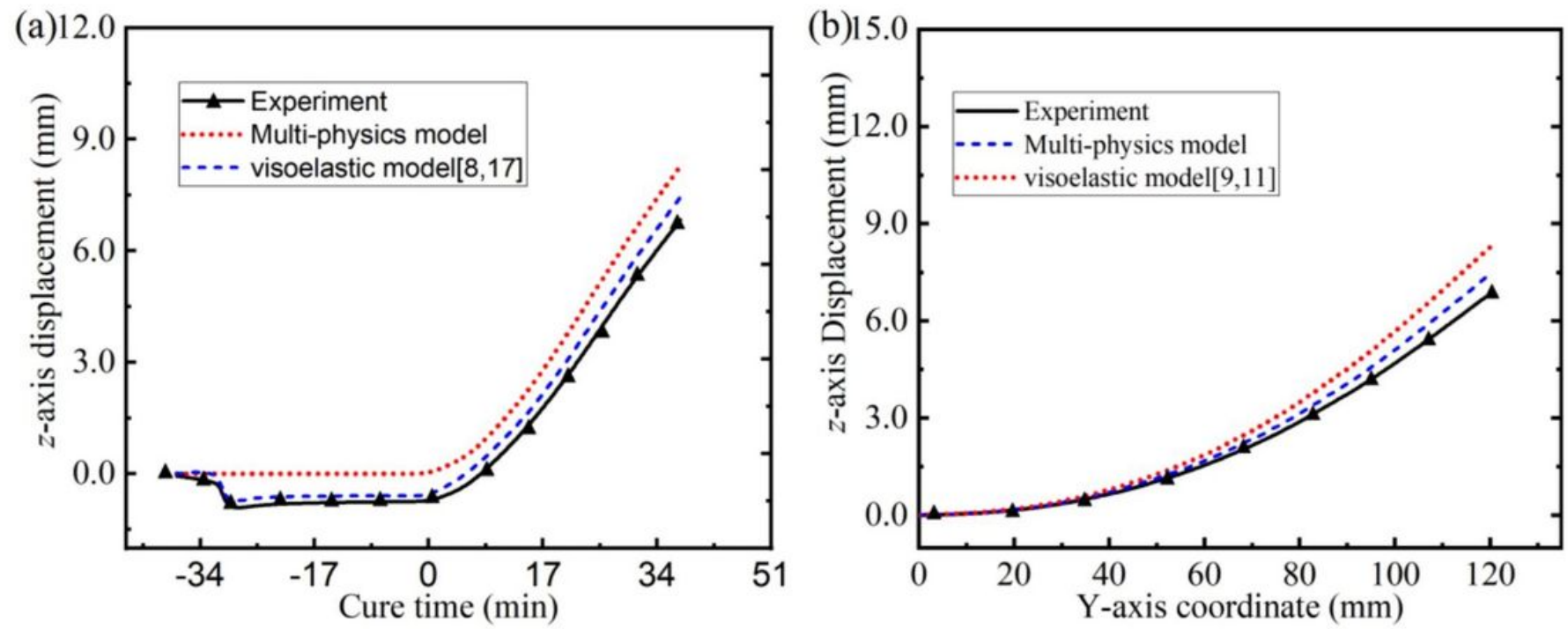
Figure 7

Z-axis displacement variation on the middle section obtained by different methods. a Displacement variation of M-point with time. b Final z-axis displacement of the middle section
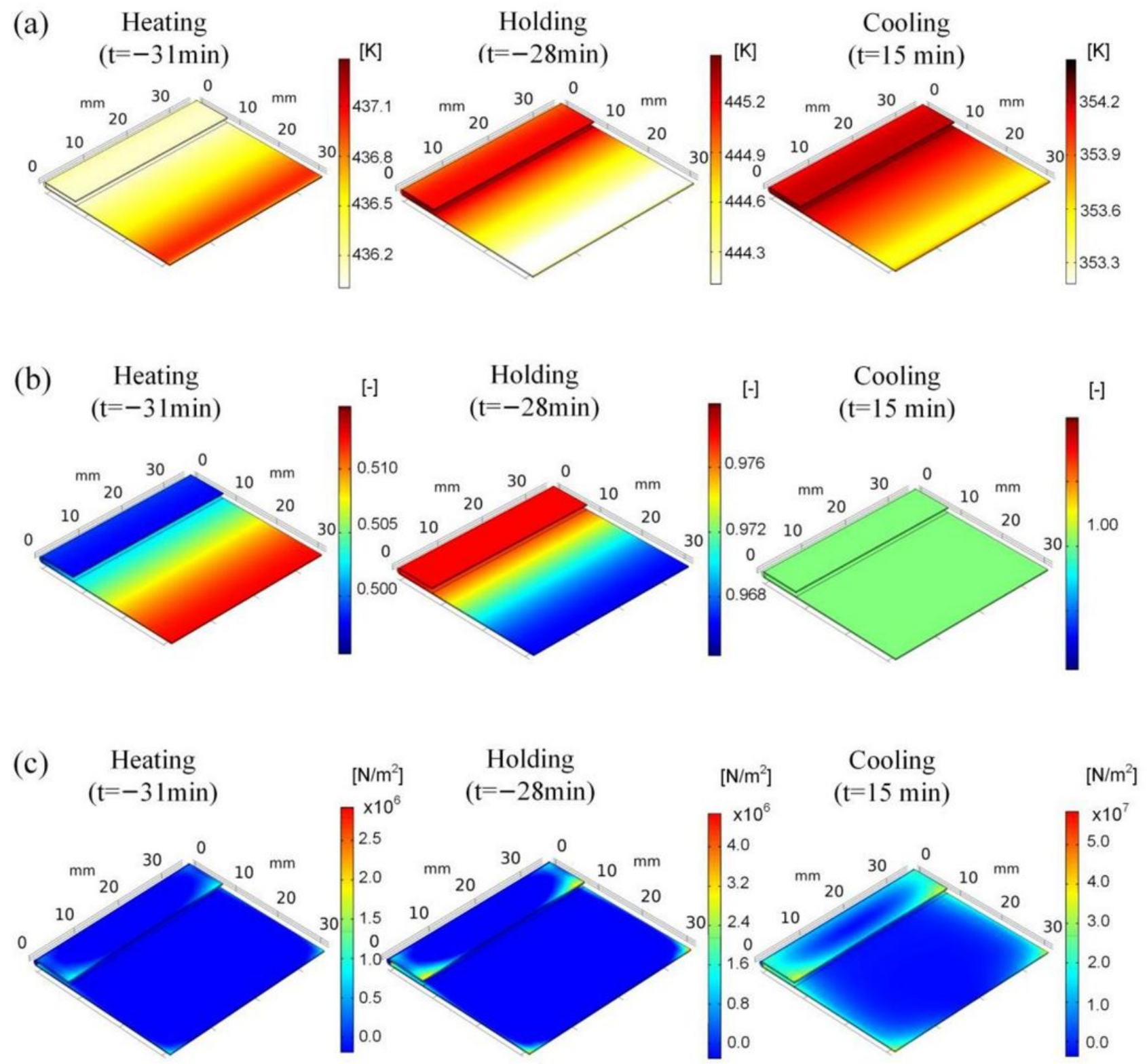

\section{Figure 8}

Physical fields of the adhesive at different curing stages. a Temperature field. b Curing degree field. c Von Mises stress field 


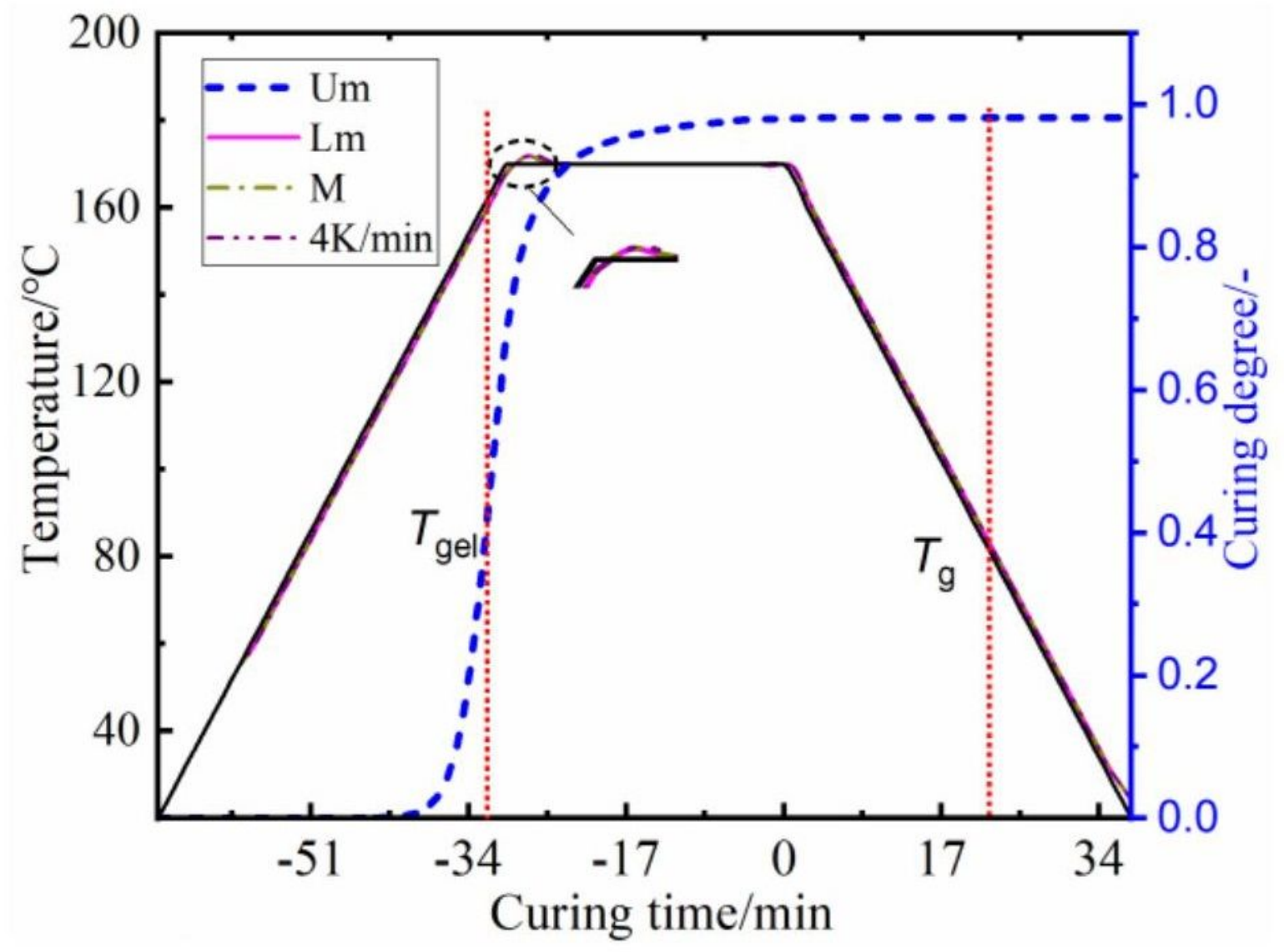

Figure 9

Evolution of temperature and curing degree of the adhesive layer 


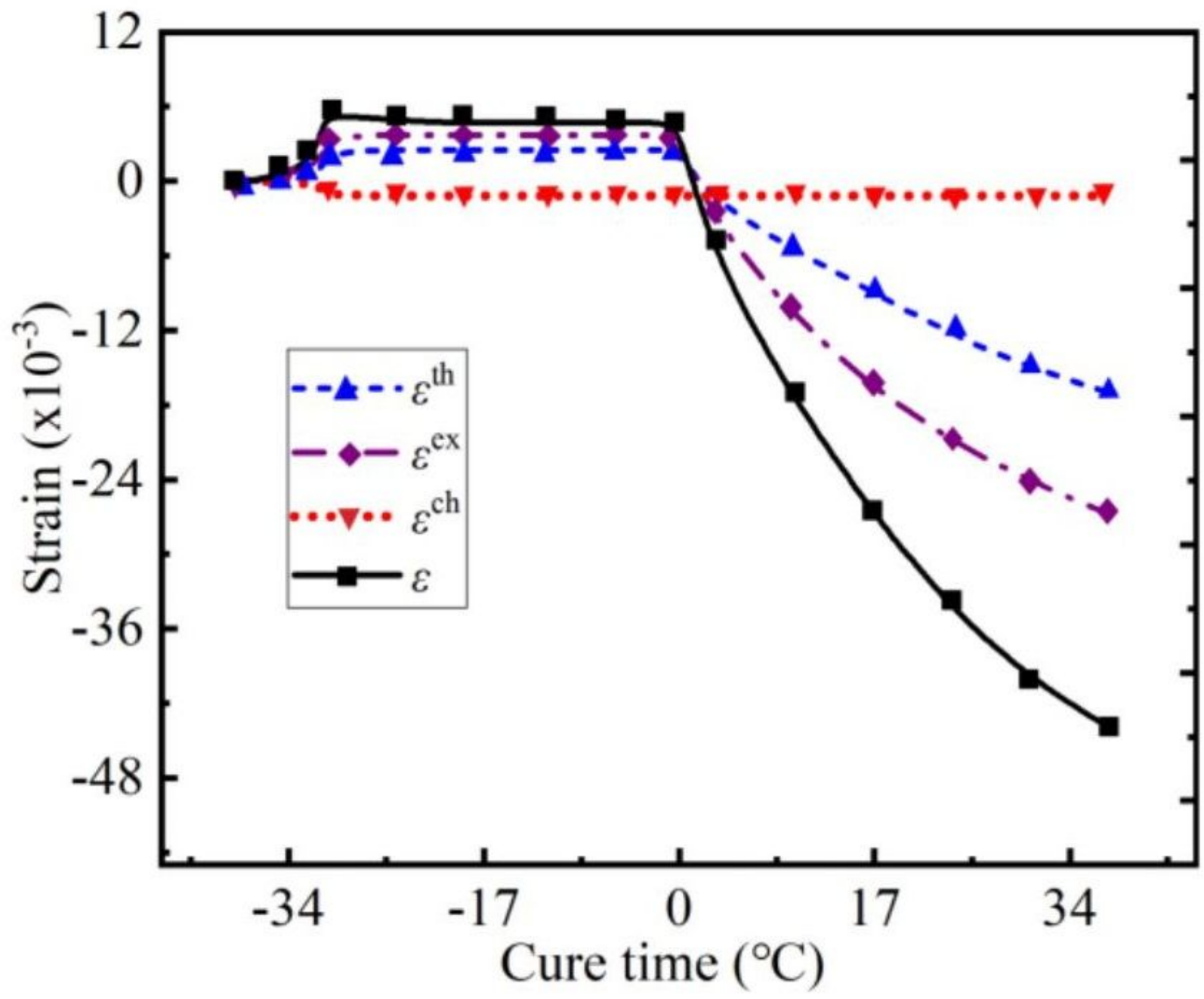

Figure 10

Evolution of strain at point Um under temperature cycle
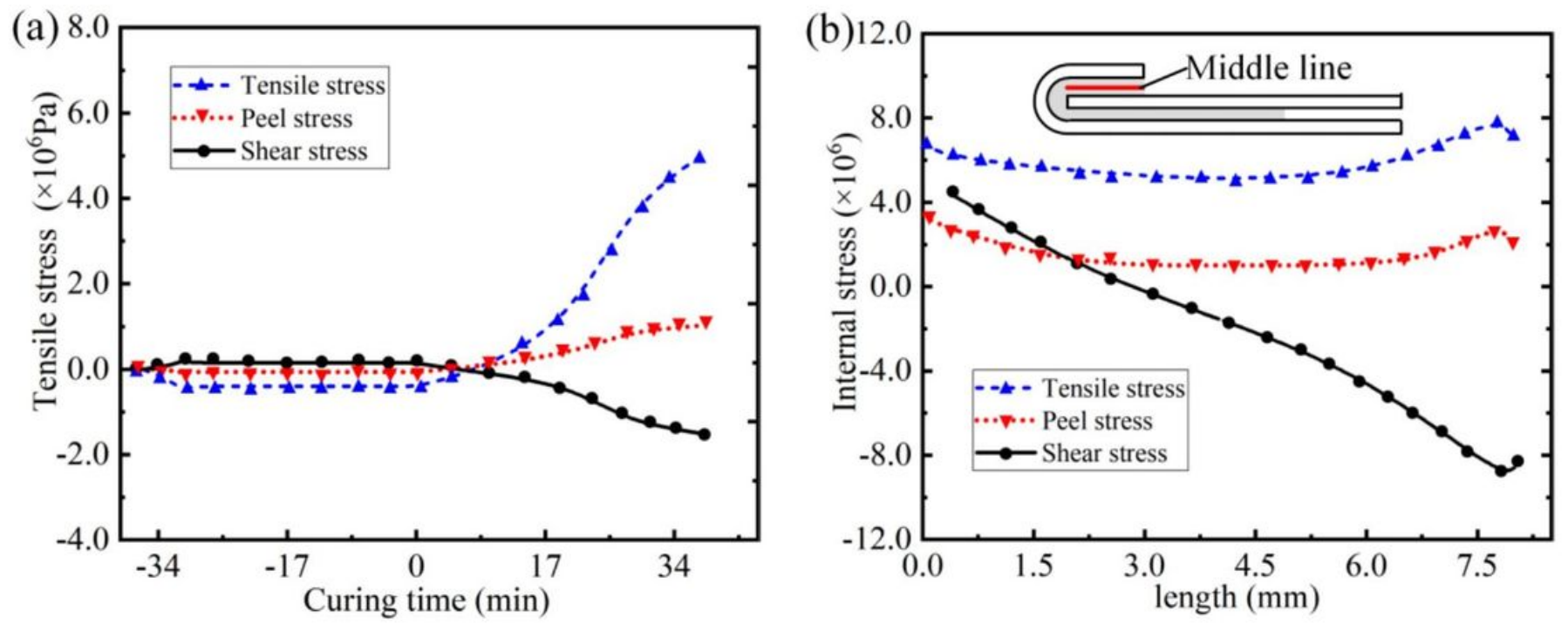


\section{Figure 11}

Variation of internal stress of the upper adhesive layer on the middle section. a Variation of different stresses at point Um. b Final internal stress at the middle line
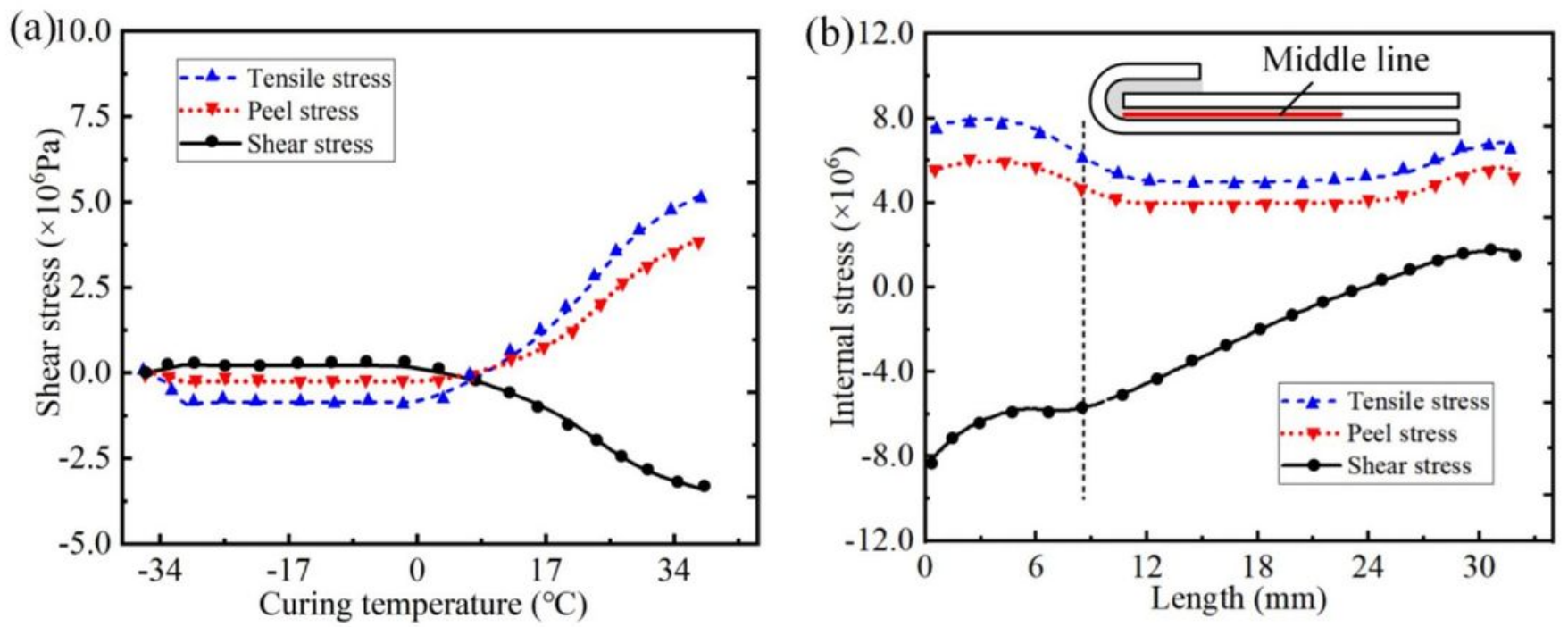

Figure 12

Variation of internal stress of the upper adhesive layer on middle section. a Variation of different stresses at point Um. b Final internal stress at middle line

(a)

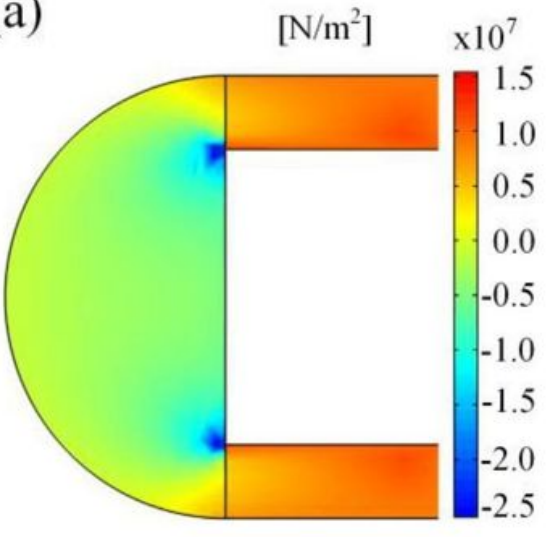

(b)

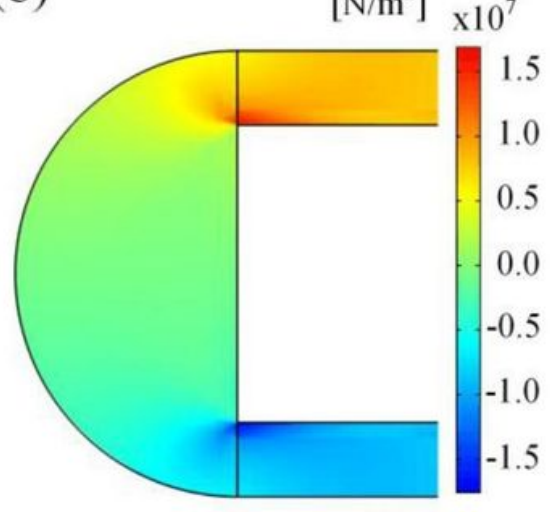

(c) $\left[\mathrm{N} / \mathrm{m}^{2}\right] \quad \times 10^{7}$

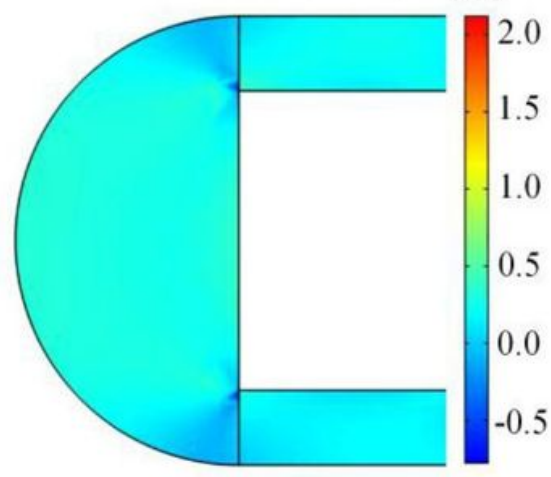

Figure 13

Final internal stress at the circular corner. a Tensile stress. b Shear stress. c Peel stress 

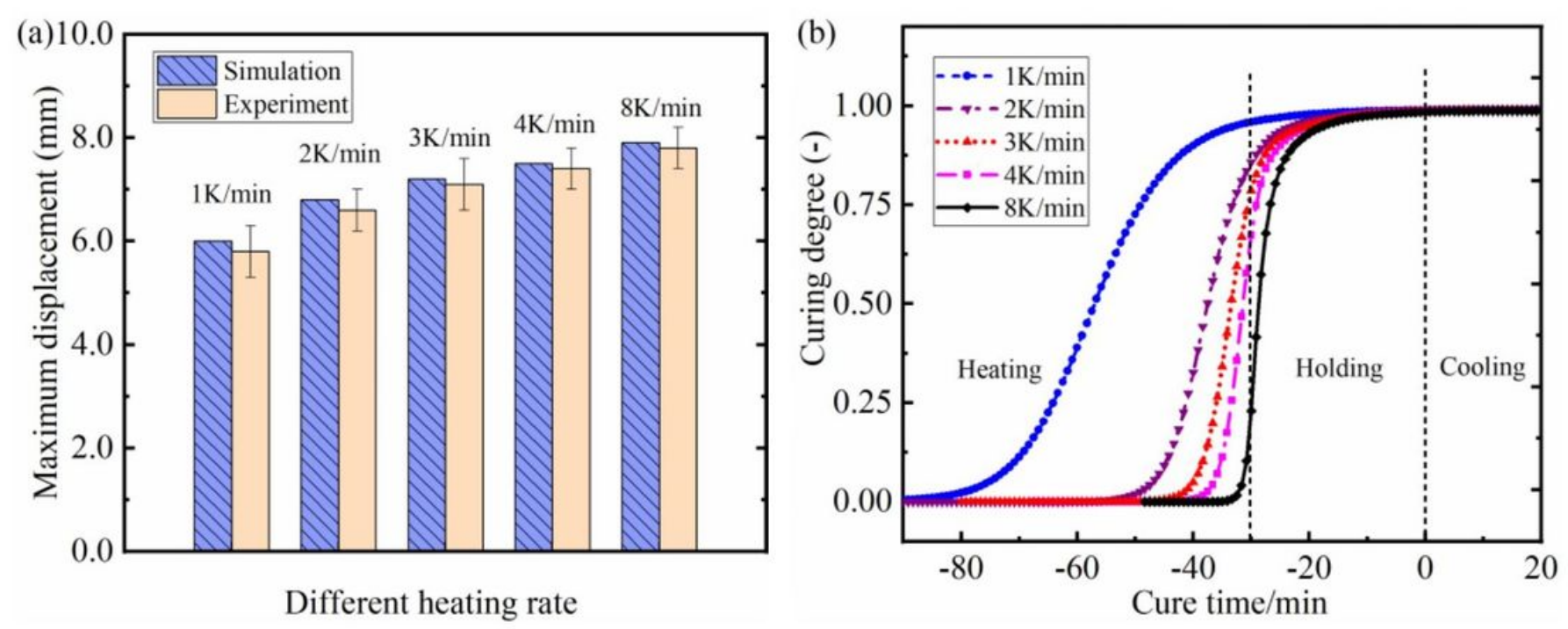

\section{Figure 14}

Maximum displacement and curing degree curves at holding temperature 170 \. a Maximum displacement under different heating rates. $b$ Curing degree curves

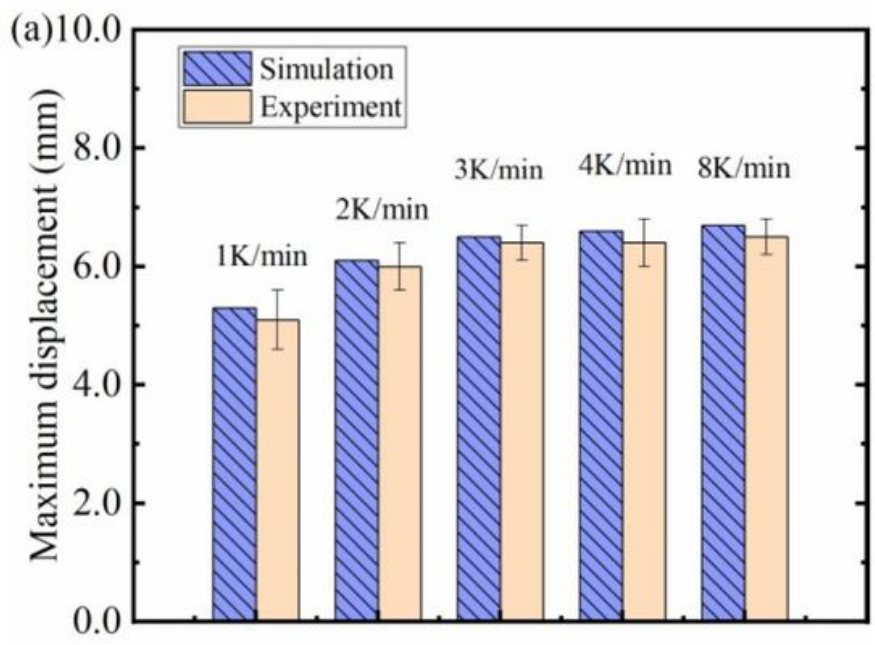

Different heating rate

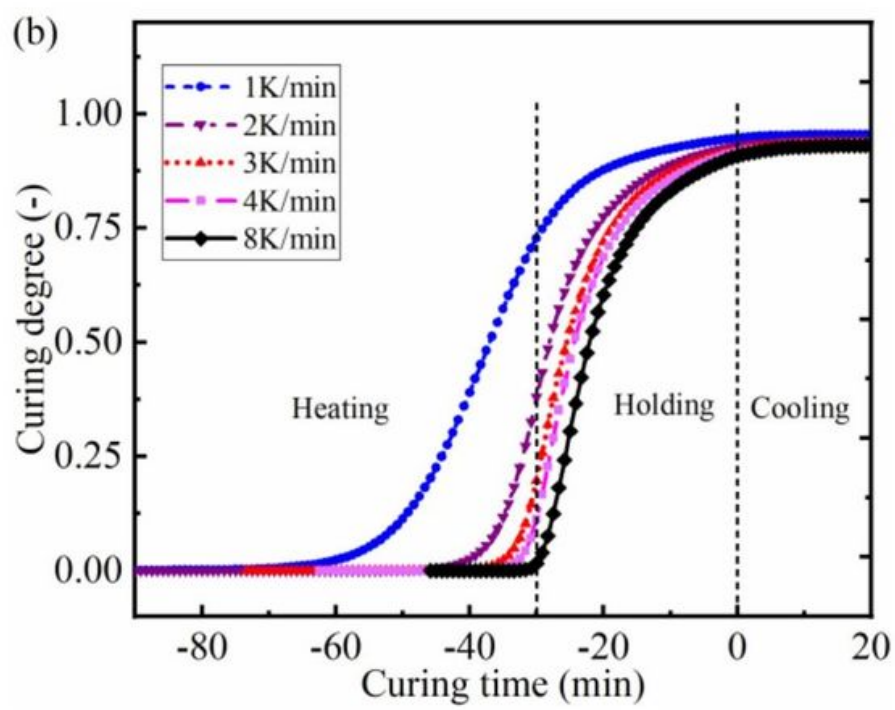

Figure 15

Maximum displacement and curing degree curves at holding temperature 150 \. a Maximum displacement under different heating rates. $b$ Curing degree curves 